\title{
Myoanatomy of three aberrant kinorhynch species - similar but different?
}

\author{
Maria Herranz ${ }^{1,2^{*}}$, Katrine Worsaae ${ }^{1}$, Taeseo Park ${ }^{3}$, Maikon Di Domenico ${ }^{4}$, Brian S. Leander ${ }^{5}$, \\ Martin V. Sørensen²
}

\author{
${ }^{1}$ Department of Biology, University of Copenhagen, Copenhagen, Denmark; ${ }^{2}$ Natural History Museum of Denmark, \\ University of Copenhagen, Copenhagen, Denmark; ${ }^{3}$ National Institute of Biological Resources, Incheon, South \\ Korea; ${ }^{4}$ Centro de Estudos do Mar, Universidade Federal do Paraná, Pontal do Paraná, Brazil; ${ }^{5}$ Departments of \\ Zoology and Botany, University of British Columbia, Vancouver, Canada. \\ *Corresponding author \\ E-mail: maria.herranz@bio.ku.dk; mariaherranzm@gmail.com. Orcid ID: https://orcid.org/0000-0002-3020-6072
}

\begin{abstract}
Aberrant kinorhynchs show several modifications deviating from the typical kinorhynch body plan, including a modified introvert with very elongated and flexible scalids, a weakly developed neck, and a slender trunk with less distinct segmentation. How these aberrant external features are reflected in the inner anatomy and how their aberrant body plan evolved is not understood. Here, we provide a comprehensive and comparative myoanatomical study of three putatively, distant related worm-like species: Cateria styx, Franciscideres kalenesos and Zelinkaderes yong. Despite the weak external segmentation of the trunk, the studied species show a distinct segmental arrangement of the musculature. However, this arrangement is shifted posteriorly with respect to the external segmentation, because the extremely thin and flexible cuticle is lacking the apodeme-like cuticular thickenings (pachycycli) where the longitudinal muscles usually attach. The muscular arrangement in the three species is overall similar, yet, C. styx show most resemblance to the allomalorhagid F. kalenesos, whereas the cyclorhagid $Z$. yong differs in several ways. This suggests a closer relationship of $C$. styx to Allomalorhagida. Whereas most kinorhynchs prefer muddy sediments, both the allomalorhagid and cyclorhagid worm-like kinorhynchs are mainly found in sandy environments, suggesting that a flexible, slender body evolved at least twice independently as an adaptation to the interstitial environment.
\end{abstract}

\section{Keywords}

Mud dragons, segmentation, musculature, meiofauna, CLSM, F-actin

\section{Declarations}

\section{Funding}

This project received funding from the European Union's Horizon 2020 research and innovation programme, under the Marie Sklodowska-Curie grant agreement No 797140 to MH. Sampling in South Korea was funded by the Carlsberg Foundation to MVS (CF17-0054). CLSM facilities were supported by the Villum foundation (Grant \# 102544) and the Carlsberg 
Foundation to KW (CF15-0946). CLSM imaging at the University of British Columbia was funded by the Hakai Institute (Tula foundation) and the National Science and Engineering Research Council of Canada (NSERC 2019-03986) to BSL.

\section{Conflicts of interest}

The authors declare that they do not have any conflict of interest.

\section{Availability of data and material}

All data analysed during this study is included in the present contribution and its associated files (online resources 1 and 2).

\section{Authors' contributions}

$\mathrm{MH}, \mathrm{MVS}, \mathrm{KW}$ conceived the study. MH, MVS, KW, TP, and MDD collected specimens from South Korea and Brazil. MH prepared and performed the experiments and imaging at the University of Copenhagen and University of British Columbia. MH prepared all figures and 3D reconstructions. MH, MVS, and KW drafted the manuscript. All authors have proofed and approved the final version of this manuscript.

\section{Acknowledgments}

We are grateful to the Bioimaging facility of University of British Columbia, to the Unidade Integrada de Imagens and Laboratorio de Invertebrados from Instituto de Biodiversidade e Sustentabilidade, Federal University of Rio de Janeiro UFRJ (NUPEM/UFRJ - Macaé) for offering laboratory space; and to Center for Marine Studies, Federal University of Paraná (CEM/UFPR) for offering lab space and student support with field collections in Pontal du Sul in 2015 and 2019. 


\section{Introduction}

Kinorhynchs, commonly named mud dragons, have a quite conserved body plan with three well differentiated regions: a head, a neck, and a segmented trunk. However, some genera with a characteristic worm-like appearance, exhibit significant modifications in one or more of these regions including: (i) introverts with reduced number of scalids; (ii) extremely long and flexible primary spinoscalids; (iii) neck with poorly developed or lacking placids; (iv) slender trunk with very thin cuticle, and (v) less distinct external segmentation (Dal Zotto et al. 2013; Neuhaus and Kegel 2015; Herranz et al. 2019; Yamasaki 2019).

The increasing number of observations and availability of worm-like species has led to questions about the adaptive functionality and evolution of the aberrant body plan in Kinorhyncha. The first aberrant, worm-like kinorhynch species described was Cateria styx Gerlach, 1956, collected intertidally from a sandy beach in Macaé, Brazil (Gerlach 1956). C. styx possesses several unusual and distinct characters including a very thin cuticle, a different arrangement of tergal and sternal plates in the trunk, neck without differentiated placids, introvert modifications, and a unique dorsal organ (Gerlach 1956; Herranz et al. 2019). The genus accommodates one additional species, C. gerlachi Higgins, 1968, that also lives intertidally and is described from a sandy beach in Waltair, India (Higgins 1968). Additional aberrant genera are: Zelinkaderes described by Higgins (1990), with five species from sandy and muddy sediments; Triodontoderes described by Sørensen \& Rho (2009) with two species from coarse sediment in Micronesia (Sørensen and Rho 2009) and the Caribbean (Cepeda et al. 2019); and the monotypic genera Franciscideres described by Dal Zotto et al. (2013) and Gracilideres described by Yamasaki (2019) from coarse sediments in Brazil and in Japan, respectively.

The most recent phylogenetic analysis combining molecular and morphological data suggested Franciscideres and Gracilideres as sister groups nested within the Allomalorhagida ("new genus" in Sørensen et al. 2015); this result supported previous molecular analyses by Dal Zotto et al. (2013) and Yamasaki et al. (2013) where Gracilideres is referred to as "undescribed" or "new genus" respectively. On the contrary, Zelinkaderes, Triodontoderes and Cateria were nested within Cyclorhagida (Sørensen et al. 2015). However, the lack of molecular data for Cateria makes its position within Cyclorhagida contentious because morphological similarities suggest a closer relationship with Franciscideres and Gracilideres (Sørensen et al. 2015; Yamasaki 2019). 
Most studies on aberrant kinorhynchs have focused on their taxonomy, external morphology, phylogeny and ecology (Dal Zotto et al. 2013; Neuhaus and Kegel 2015; Sørensen et al. 2015; Herranz et al. 2019; Lopes Mello et al. 2019; Yamasaki 2019; Rucci et al. 2020), but little is known about their internal morphology. Only some aspects of Cateria styx and two other Zelinkaderes species (Zelinkaderes brightae Sørensen et al., 2007 and Zelinkaderes floridensis Higgins, 1990) have been studied using confocal laser scanning microscopy (CLSM) and transmission electron microscopy (TEM) (Neuhaus 1994; Herranz et al. 2013, 2019). Kinorhynchs with well-defined outer trunk segmentation also have correlating and segmentally arranged organ systems such as the musculature or the nervous system (Nebelsick 1993; Müller and Schmidt-Rhaesa 2003; Herranz et al. 2013, 2014, 2019, 2020; Altenburger 2016). However, it is still unclear how the internal morphology is organized in worm-like kinorhynchs with a thin cuticle and poorly differentiated trunk segments. With kinorhynchs being the only segmented taxon within the major ecdysozoan clade Cycloneuralia, investigations of the internal morphology of aberrant kinorhynchs are thus relevant to understand the evolution of segmentation, not only within Kinorhyncha but also within Ecdysozoa.

The aim of the present study is to investigate if the external morphology that characterises aberrant kinorhynchs is correlated with modifications in the arrangement of the internal organ systems. Here, we focus on the muscular system, using CLSM and F-actin staining to reconstruct three-dimensionally the myoanatomy of three species and genera: $C$. styx, F. kalenesos Dal Zotto et al., 2013 and Zelinkaderes yong Altenburger et al., 2015. Through examination and comparison of distantly related representatives of both Allomalorhagida and Cyclorhagida, we establish hypotheses on putative convergences and homologies in the musculature and anatomy of worm-like Kinorhyncha and their adaptations to the interstitial environment. 


\section{Materials and Methods}

\section{Sampling}

Specimens of Zelinkaderes yong were collected in May 2018 intertidally from fine sand, at

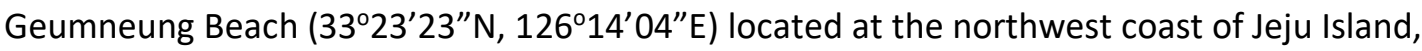
South Korea. Sediment samples were collected by hand. Specimens of Franciscideres kalenesos were collected in March 2015 and January 2019 from sandy beaches in Guaratuba, Brazil by the end of "Rua Bolivia", and in Pontal do Paraná, Brazil "Praia das Gaivotas" (2555'47"S, $48^{\circ} 34^{\prime} 48^{\prime \prime} \mathrm{W} ; 2^{\circ} 43^{\prime} 07^{\prime \prime} \mathrm{S}, 48^{\circ} 28^{\prime} 49^{\prime \prime} \mathrm{W}$, respectively). Sediment samples were collected subtidally from the surf zone area by hand. Specimens of Cateria styx were collected in March 2015 at Cavaleiro Beach by the end of the street “Rua Bariloche" in Macaé, Brazil (22²1'59"S, $\left.41^{\circ} 46^{\prime} 27^{\prime \prime} \mathrm{W}\right)$. Sediment samples were collected from $50-70 \mathrm{~cm}$ deep holes dug on the beach, 3 meters below the high tide mark. At all sampling localities, kinorhynchs were extracted from the sediment by stirring vigorously an equal mix of sediment and sea water in a bucket, letting the sediment deposit, and filtering the supernatant immediately after through a $60 \mu \mathrm{m}$ mesh. The concentrated meiofauna was sorted while the specimens were still alive.

\section{Histochemistry and confocal laser scanning microscopy (CLSM)}

Specimens of C. styx, F. kalenesos and Z. yong were isolated from live samples, relaxed with a $\mathrm{MgCl}_{2}$ solution for 5-10 minutes and fixed in 4\% Paraformaldehyde (PFA) in filtered sea water for 40-50 min at room temperature. Posteriorly, the specimens were washed at least three times in phosphate buffered saline (PBS) and stored at $4^{\circ} \mathrm{C}$ in PBS with $0,05 \%$ of Sodium azide $\left(\mathrm{NaN}_{3}\right)$ to prevent microbial growth.

Myoanatomical studies were carried out with selected specimens of each species (25 C. styx, 16 F. kalenesos and 10 Z. yong). Specimens were first incubated in PBT (PBS $1 x+0.25 \%$ bovine serum albumin $+1 \%$ Triton $\mathrm{X}-100$ ) for 30 minutes at room temperature. Posteriorly, the specimens were transferred to a mix of 0.33M Alexa Fluor ${ }^{\circledR}$ either 488- or 633-labeled phalloidin (Invitrogen, Carlsbad, USA) in PBT and incubated at room temperature for 72 hours in glass spot plates. Prior to mounting, the specimens were rinsed several times in 1x PBS. 
In order to guide interpretations of the myoanatomy of each species, imaging of the cuticle was carried out in combination with the musculature. In Alexa Fluor ${ }^{\circledR} 633$ stainings, the autofluorescence of the cuticle was acquired as a separate channel with an excitation wavelength of $488 \mathrm{~nm}$. In specimens stained with Alexa Fluor ${ }^{\circledast} 488$, the cuticle signal was captured together with the phalloidin signal.

For CLSM imaging, specimens were individually mounted on glass slides in Vectashield ${ }^{\circledR}$ antifade mounting medium containing DAPI (Vector Laboratories, Burlingame, USA). Specimens were imaged using an Olympus IX 8 inverted microscope in combination with a FluoView FV1000 confocal system at the Biological Institute, University of Copenhagen; and an Olympus FV1000 Multiphoton CLSM at the UBC Bioimaging Facility. Z-stacks were analysed and composed with FIJI, version 2.0 (Wayne Rasband, National Institutes of Health). Threedimensional reconstructions were surface rendered from Z-stacks, segmented and labelled in Amira 6.0 (FEI, SAS). Original CLSM micrographs were edited (e.g., levels, rotation plane, contrast and brightness) with Adobe Photoshop CS6 (Adobe Systems Incorporated, San Jose, CA) and Fiji. Figure plates were assembled in Adobe Illustrator CS6 (Adobe Systems Incorporated, San Jose, CA).

Positional information used for the identification of external and internal anatomy, followed the commonly accepted terminology for kinorhynchs compiled in Sørensen and Pardos (2020).

\section{Scanning electron microscopy (SEM)}

Ten specimens of $F$. kalenesos fixed in 4\% PFA were dehydrated through a water-ethanol series, and transferred to acetone through an ethanol-acetone series, critical point dried, mounted on aluminium stubs, sputter coated with a mix of platinum-palladium and examined under a JEOL JSM-6335F Field Emission SEM.

SEM specimens of Z. yong and C. styx from Altenburger et al. (2015) and Herranz et al. (2019) stored in MVS' collection were re-examined. Additional SEM photos of $Z$. yong were kindly provided by Andreas Altenburger. 


\section{Results}

The three selected species Z. yong, F. kalenesos and C. styx are characterized externally by their vermiform appearance with very elongated trunk, circular in cross section, modified introvert and neck, extremely thin cuticle and less distinct trunk segmentation (Fig. 1). For detailed external descriptions of Z. yong see Altenburger et al. (2015); for F. kalenesos see Dal Zotto et al. (2013) and Rucci et al. (2020); for C. styx, see Higgins (1968), Neuhaus and Kegel (2015) and Herranz et al. (2019). Detailed data of all myoanatomical studies on kinorhynchs to date, including the results presented herein, are compiled in Table 1.

\section{Myoanatomy of Z. yong}

\section{Introvert}

The introvert in Z. yong is supplied by several muscles including ten primary spinoscalid muscles, ten spinoscalid retractors, ten bundles of long retractors, three circular muscles and twelve short retractors. The primary spinoscalid muscles (psm) are intrinsic to each of the ten primary spinoscalids. They originate on the proximal part of the basal spinoscalid piece, and insert at the base of the distal end-piece, therefore allowing independent movement of each primary spinoscalid (Fig. 2a, c, g). The primary spinoscalid muscles reach their maximum length when the introvert is retracted in the trunk and the spinoscalids are straight (Fig. $2 \mathrm{a}, \mathrm{g})$. The spinoscalid retractors (sr) are a V-shaped when the introvert is retracted (Fig. 2a), inserting alternate to the primary spinoscalids and originating at the introvert base. The introvert long retractors (ilr) are grouped into ten bundles of four muscles each, including two thick and two thin muscles. The ten bundles originate adjacent to the $\mathrm{V}$-shaped spinoscalid retractors, and extend posteriorly to insert trunk segments 4-8 in laterodorsal/midlateral and ventromedial positions, respectively (Fig. 2a, c, g; 3a-b). The introvert circular muscles (icm) insert at the posteriormost part of the introvert cuticle (Fig. 2a, b). Their position varies depending of the degree of extension of the introvert, being posterior to the neck muscles when the introvert is retracted and anterior when the introvert is extended (Fig. 2a-b; 3f). The introvert short retractors (isr) are radially arranged. They originate anteriorly adjacent to the introvert circular muscles of the introvert, and insert posteriorly to the cuticle of segment 1 (Figs 2a-b, $f, 3$ ). 
Musculature associated with the mouth cone and gut in Z. yong includes nine pairs of outer oral style longitudinal muscles, nine short basal oral style muscles, one circular muscle, inner oral style muscles, a pharyngeal bulb surrounded by pharynx associated muscles, and intestine associated muscles. A pair of outer oral style muscles (osm), is associated with each of the nine outer oral styles and situated along their most proximal part (Fig. 2a, g). The short basal outer oral style muscles (bosm) lay in between the bases of the outer oral styles, associated with soft cuticle (Fig. 2g). A circular muscle is present at the basal part of the outer oral styles, situated internally respect to the other muscles (osm, bosm) and is composed of three fibres.

Additionally, associated with the base of the inner oral styles there are several short muscles arranged in a ring-like structure (iosm). The anterior part of the ring-like structure shows short muscle fibres extending towards the first inner oral styles ring (also referred at as ring -01). These muscles are arranged in pairs and form a triangular shape giving the appearance of a crown with five tips, where each of the tips correspond with the position of an inner oral style.

(Figs $2 \mathrm{~g}$; 3a-b, g). The pharyngeal bulb (pb) is situated below the inner oral styles and composed of approximately fifteen alternating circular and radial muscles (Figs 2a, g; 3a-b, g). The pharyngeal lumen is circular in cross section. Several muscles supply the pharynx externally: pharynx retractor muscles, pharynx longitudinal muscles and gut longitudinal muscles. Eight to ten pharynx retractors (pr) originate radially adjacent to the anteriormost part of the pharyngeal bulb, and extend to segments 3-5, where they insert centrally (Figs $2 \mathrm{~g}$; $3 a-b, g)$. When the pharynx is retracted into the trunk, these muscles are relaxed and get a wavy appearance (Figs $2 \mathrm{~g} ; 3 \mathrm{a}-\mathrm{b})$. Ten pharynx longitudinal muscles $(\mathrm{plm})$ originate from the posterior part of the pharyngeal bulb and insert at the posteriormost part of the mouth cone (Fig. 2a). Contraction of these muscles will shorten the pharyngeal bulb longitudinally. The gut longitudinal muscles (gl), surrounding the oesophagus and intestine, originate along the anterior third of the pharyngeal bulb and extend posteriorly towards segment 11 . Multiple circular muscles encircle the longitudinal muscles of the gut forming a gut grid (gg) (Fig. 2a, d). The hindgut is associated with several muscles. Two pairs of muscles extend ventrally from their subdorsal origin in segment 10 and are interpreted as hindgut dilators (hd) (Figs 2a, j, j"; 3a-b). The dorsoventral muscles in segment 11 also seem to supply the hindgut (Fig. 2e, j, j"). A set of muscles forming a triangular-shape is situated medially in segment 11 surrounding the hindgut, interpreted to be hindgut constrictors (hc) (Figs 2e, j, j"; 3a-b). 
The neck region contains three thin circular muscles $(\mathrm{nm})$. The two posterior muscles are consistently interrupted in paraventral position, whereas the anteriormost muscle is the only one forming a complete ring (Figs $2 b, f ; 3$ ).

Trunk

The trunk region in Z. yong is composed of several sets of muscles including dorsal, ventral, dorsoventral and lateral muscles. Some of the longitudinal muscles seem to expand across segments, whereas the dorsoventral muscles are segmentally arranged. The longitudinal muscles are arranged in separate sets, each of them composed of a single or several muscles. Eighteen longitudinal muscle sets originate at the anterior part of segment 1, where eight are dorsal, eight ventral and two lateral (Figs $2 f, h ; 3$ ). The only muscle sets composed of single muscles are situated in ventromedial positions (Figs $2 f ; 3 c-d, f$ ). The dorsal, lateral and ventral longitudinal muscles originate in a transverse zone at the anterior $1 / 3$ of the tegumental plates, extend across the intersegmental region, and insert in corresponding positions at the following segment. In this way, the segmental arrangement of the musculature is shifted $1 / 3$ segment length in relation to the external, cuticular segment differentiation (Figs 2f-h; 3c-d). The posterior insertion point of a longitudinal muscle is furthermore situated so close to the origin of the following muscle that it gives the illusion of several long and draped continuous muscles that extend through the entire trunk. The attachment points for these muscles form small muscular "scars" visible externally on the cuticular surface of each segment and detectable with SEM (seen as cuticular depressions in Figs $2 \mathrm{~h}-\mathrm{i}$ ). From segments 5 to 10 the dorsal and ventral longitudinal muscle sets become less distinguishable, forming two subdorsal and ventromedial groups respectively (Fig. $3 \mathrm{~b}$ ). The lateral muscle bundles arise from midlateral to laterodorsal positions on segments 1-7 adjacent to the dorsal insertion of the dorsoventral muscles (Fig. 3d, e). However, it is not clear whether all the lateral muscles maintain a segmental arrangement in all the segments. Paired dorsoventral muscles are present from segments 2 to 11 and are composed of 3 fibres each, except for segments 2 and 3 , where the muscles are shorter and limited to one or two fibres (Figs $2 a, f, j ; 3$ ). All the muscles have paraventral attachments but insert progressively more dorsal. On segments 2-3 the insertion points of the dorsoventral muscles are midlateral and reach a subdorsal position on segments 10-11 (Fig. 2d-e). 
Additional muscles of the trunk supply the terminal spines. The midterminal spine is at its base supplied by a pair of diverging muscles $(\mathrm{mtm})$ that insert in the anterior part of segment 11 (Figs 2j-j"; 3a-b). A pair of muscles (Itam) supplies the lateral terminal accessory spines. These muscles originate at the base of the lateral terminal accessory spines and insert adjacent to the insertion of the midterminal spine (Fig. $\left.2 \mathrm{j}-\mathrm{j}{ }^{\prime \prime}\right)$. Based on the position and arrangement of the muscles we interpret that the midterminal and lateral terminal accessory spines can only move in the lateral plane. Lateral terminal spines do not seem to be directly supplied by any muscles.

Moreover, weak F-actin labelling was found in the distal part of the cuspidate spines in the shape of a ring, indicating the presence of contractile tissue (Fig. 2j'). Non-muscular labelling shows paired cylinder-shaped structures congruent with the position of sensory spots.

\section{Myoanatomy of F. kalenesos}

Introvert

The introvert of $F$. kalenesos is supplied by ten spinoscalid retractors, ten bundles of long retractors, four to five circular muscles and fourteen short retractors. However, no muscles supply the primary spinoscalids. The spinoscalid retractor muscles (sr) are $\lambda$-shaped and originate at the introvert cuticle at the level of the second spinoscalid ring, alternating with the primary spinoscalids (Figs $4 a ; 5 a-b$ ). When the introvert is inverted the spinoscalid retractor muscles become $y$-shaped (Figs 4a; 5a). The introvert long retractor muscles (ilr) originate at the level of the second row of spinoscalids and extend posteriorly towards segments 3 or 5-6 inserting in midlateral/laterodorsal positions, adjacent to the dorsoventral muscles (Figs 4a; $5 b, e)$. On segment 4 , the long retractor muscle attachments are displaced dorsally, adjacent to the laterodorsal longitudinal muscles (Figs 4d; 5c). The introvert circular muscles (icm) are thin and their positions vary depending on the level of introvert eversion/retraction (Figs 4a-b, d; 5a-b). When the introvert is everted, the most anterior introvert circular muscles are situated underneath the second spinoscalid ring and the most posterior ring is situated under the last spinoscalid ring (Fig. 5b). The introvert short retractor muscles (isr) originate anteriorly adjacent to the posteriormost circular muscle, and extend posteriorly towards segment 1 where they insert centrally (Figs 4a-b; $5 a-b$ ). When the introvert is everted, these muscles 
reach their maximum length (Figs $4 a, 5 b$ ), and when the introvert is retracted they have a wavy appearance (Fig. 4b).

\section{Mouth cone and gut musculature}

The musculature associated with the mouth cone includes two circular muscles, a number of mouth cone retractors, a pharyngeal bulb, pharynx-associated muscles and intestine associated muscles. All these structures are moveable and their positions change in an anterior-posterior direction. The mouth cone shows two circular muscles (mcc), one at the base of the outer oral styles and another at the base of the inner oral styles (Fig. 4c). Additionally, there are several mouth cone retractors that originate from laterodorsal and ventrolateral positions in segments 3-6 and extend inserting at the base of the mouth cone (Figs 4c; 5e). The pharyngeal bulb (pb), is very elongated and composed of ca. twenty-two alternating radial and circular muscles (Fig. 4c); the lumen is circular in cross section. Pharynx longitudinal muscles and gut longitudinal muscles supply and surround the pharyngeal bulb. The pharynx longitudinal muscles $(\mathrm{plm})$ originate at the base of the pharyngeal bulb and insert at the base of the mouth cone (Fig. 4c). The gut is surrounded by a net of longitudinal and circular muscles forming a gut grid (gg) (Fig. 4d). The gut longitudinal muscles (gl) originate adjacent to the pharyngeal bulb and extend towards the hindgut. In segment 10 , associated with the hindgut, there is a circular-like muscle identified as a hindgut constrictor (hc). Additionally, a pair of dorsal muscles originate from the dorsal part of segment 10 and insert at the hindgut; these are interpreted as hindgut dilators (hd) (Fig. 4d, h).

\section{Neck}

The neck, which has the appearance and length of a segment, has a circular muscle $(\mathrm{nm})$ situated in a central position (Figs $4 a$, b, d; 5a-b). Longitudinal sets of dorsal, ventral and lateral muscles originate adjacent to the circular muscle leaving distinct oval muscular scars in the cuticle (Fig. 4e), and attach in the anterior part of segment 1 (Fig. 5a, c-d). 
Every trunk segment in F. kalenesos shows longitudinal (dorsal, ventral) and dorsoventral sets of muscles, except for segment 11 that lacks dorsal and ventral muscles. Most of the longitudinal muscles are segmentally arranged, although this segmentation is shifted approximately $1 / 3$ of a segment length when compared with the external cuticular segmentation (Figs 4g; 5c). Dorsal muscles are distributed in two bundles along the subdorsal position (Figs 4d, g; 5c-d). Ventral muscles are more compacted forming bundles in ventromedial/ventrolateral areas. Additionally, lateral longitudinal muscles (lam) are present in segments 1 to 9 adjacent to the ventral longitudinal muscles in a ventrolateral/sublateral position (Figs 4d; 5c-d). Dorsal, ventral and lateral longitudinal muscles originate in the anteriormost part of one segment and extend towards the anterior third of the following segment where they insert leaving distinct round to oval muscular "scars" visible externally on the cuticle (Fig. 4f). The dorsoventral muscles (dv) are paired, segmentally arranged and composed of four to five fibres in most segments, except for segments 1 and 9-11 which have three or less fibres each (Figs 4d; 5d). The dorsoventral muscles originate ventromedially and extend dorsally to insert midlaterally in segments 1-8 and laterodorsally in segments 9-11, leaving elongated muscular "scars" on the cuticle (Fig. 4f, marked with an arrow). Segment 11 has no dorsal or ventral sets of muscles but it shows at least a pair of strong longitudinal muscles associated with the lateral terminal accessory spines (Itam), interpreted as levator muscles. These muscles originate at the base of the lateral terminal accessory spines and insert to the posterior edge of the tergal plate, in the posterior part of segment 11 (Fig. 4h). The lateral terminal spines do not seem to be directly associated with any muscle; however, live observations show that both the lateral terminal and lateral terminal accessory spines are able to move posteriorly 90 degrees in a synchronized way during forward movement (Online resource 1). The closeness of the attachment points from the lateral terminal and lateral terminal accessory spines, and the evidence of synchronized movement, suggest that both spines could be connected internally by ligaments or cuticular processes. Additionally, segment 11 shows a short transverse muscle (tm), which function is undetermined (Fig. 4h). This muscle could be associated with the hindgut and therefore be interpreted as a hindgut dilator; or be involved in the movement of the lateral terminal accessory spines.

Non-muscular F-actin labelling appears as paired cylinder-shaped structures associated with the position of all sensory spots. 


\section{Myoanatomy of C. styx}

Introvert

The introvert of $C$. styx is supplied by several sets of muscles including ten spinoscalids retractors, ten sets of long retractors, six thin circular muscles and ca. fourteen short retractors. The spinoscalid retractors (sr) are y-shaped when the introvert is retracted, they alternate in sizes between five short and five long muscles (Fig. 6b). Short and long spinoscalid retractors are distally associated with two different introvert circular muscles that are situated at the level of the second and third row of spinoscalids (Fig. 6b). The introvert long retractors (ilr) are grouped into ten bundles of three to four muscles each (Fig. 6b, d). These bundles originate anteriorly in the introvert cuticle, with their positions alternating with the ten spinoscalid retractors, and insert posteriorly to segments 4-6 in laterodorsal, midlateral and ventrolateral positions (Fig. 7a, d). The introvert circular muscles (icm) are distributed along the introvert and their positions change with the level of head eversion (Figs 6b; 7b-c). Out of the six circular muscles three supply different spinoscalid rows, one supplies the introvert short retractors, and the remaining two are located at the posteriormost part of the introvert, one below the trichoscalid level and another one at the anteriormost part of segment one. Based on their positions, the first three muscles are interpreted to be controlling the retraction of the spinoscalids together with the spinoscalid retractors. The fourth circular muscle is interpreted to reduce the diameter of the introvert, and the last two circular muscles work as closing apparatus in the absence of a well-differentiated neck. The introvert short retractors (isr) are radially arranged, and originate from the lower part of the introvert, at the level of the trichoscalids, adjacent to one of the introvert circular muscles (Figs 6b-c; 7c). Posteriorly, they insert in the central part of the tegumental plate of segment 1 . The introvert short retractors invert when the introvert is withdrawn (Fig. 6b).

\section{Mouth cone and gut musculature}

Musculature associated with the mouth cone and gut in C. styx includes two circular muscles, at least six mouth cone retractors, a pharyngeal bulb, pharynx associated muscles and intestine associated muscles. The two mouth cone circular muscles (mcc) are situated around the outer and inner oral styles (Fig. 6e). The outer oral style circular muscle is composed of four fibres while the inner oral style circular muscle has three fibres. The mouth cone 
retractors $(\mathrm{mcr}$ ) originate adjacent to the anterior part of the pharyngeal bulb, at the base of the mouth cone and extend towards ventromedial and midlateral areas of segments 4 to 6 (Fig. 6e). The pharyngeal bulb is very elongated (ca. $80 \mu \mathrm{m}$ in length), with more than twentyfive alternating circular and radial muscles and a lumen that appear circular in cross section. Pharynx-associated muscles include pharynx longitudinal muscles and gut longitudinal muscles. The pharynx longitudinal muscles (plm) originate at the posterior end of the pharyngeal bulb and extend anteriorly to insert to the basal part of the mouth cone (Fig. Ge). The gut longitudinal muscles originate adjacent to the pharyngeal bulb and extend posteriorly, surrounding the intestine. These muscles are encircled by circular muscles along the intestine forming a gut grid (gg) (Fig. 6h-j). The hindgut is associated with at least three pairs of short muscles. One pair originates from the dorsal part of segment 11, one from the ventromedial area, and one from midlateral position extending transversally towards the hindgut (Figs 6h-j; $7 a-b, e)$. These muscles are interpreted to be hindgut dilators (hd). A hindgut constrictor was not found, however the action of the dorsoventral muscles of segment 11, closely associated with the hindgut (Figs $6 \mathrm{~h}-\mathrm{j} ; 7 \mathrm{a}, \mathrm{e}$ ), might have an antagonistic function to the dilator muscles, assisting the constriction of the hindgut.

\section{Trunk}

Every trunk segment in C. styx shows sets of longitudinal (dorsal, ventral) and dorsoventral muscles (Fig. 7a). These muscles are all segmentally arranged. The dorsal and ventral longitudinal segmental muscles originate in the anteriormost part of a segment and extend posteriorly inserting at the anteriormost part of the following segment (Fig. 7a), leaving distinct marks visible on the cuticle (chevrons Fig. 6g). The dorsal longitudinal muscles (dm) can be distinguished individually and extend along subdorsal and laterodorsal areas (Fig. 7d-e). The ventral longitudinal muscles are more compact and situate in ventromedial to ventrolateral areas (Fig. 7a-c). Additionally, strong lateral longitudinal muscles (lam) are present in segments 1 to 9 and seem to extend across segments (Figs 6a; 7a, d-e). These muscles originate in a midlateral position in segments 1 to 6 and extend posteriorly in a diagonal way to insert in a ventrolateral/lateroventral position in segments 3 to 9 (Figs 6a; 7a, d-e). Segments 10-11 are devoid of lateral muscles (Figs 6a, $h$; 7a). The dorsoventral muscles are strong, composed of four to five fibres each, and insert centrally on the tegumental plate of each segment in midlateral and ventromedial positions leaving distinct elongated muscular 
scars (Fig. 6c, d, f-g, i). The dorsoventral muscles of segments 1 and 11 are smaller, with just three and two muscle fibres respectively (Fig. 6b-c, j). Segment 11 shows two pairs of short and strong longitudinal muscles overlapping each other. They originate in the midlateral area, close to the bases of lateral terminal accessory spines, and extend in an oblique way towards the posterior part of segment 11, inserting midventrally (Fig. 6h, j; 7a, e). The function of these muscles is uncertain since they are not clearly connected with any of the terminal spines. A pair of short transverse muscles (tm) seems to supply the lateral accessory spines, originating at their bases and extending towards the centre of the segment to insert midventrally (Fig. 6h, j). The transverse muscles are interpreted as putative levator muscles. Lateral terminal spines without associated musculature. The midterminal spine does not seem to be directly connected with any muscles, and its movement is therefore interpreted as indirect, accompanying the movement of segment 11 (Fig. 6a, h). Live recordings of $C$. styx (Online resource 2) do not indicate any independent movement of the midterminal spine, which supports this interpretation.

Males of C. styx show a pair of funnel-shaped phalloidin labelled structures that extend longitudinally along segments 9-10 in a lateral position. The posterior end of each structure narrows and seems to connect in laterodorsal/midlateral position to segment 10 (Fig. 6i, arrows; $6 \mathrm{j}$, dashed circle). The muscular nature of the described structures is uncertain but their position, close to the posteriormost part of the testis, and their absence in females, suggest it could be supplying the male reproductive system.

\section{Discussion}

\section{Comparative myoanatomy in aberrant kinorhynchs}

Despite sharing numerous general modifications that diverge from the typical kinorhynch anatomy, the aberrant species Z. yong, F. kalenesos and C. styx also show several differences in the organization of their underlying musculature.

Introvert and mouth cone

The introverts of the three studied species differ from the typical patterns by having extremely elongated primary spinoscalids and a reduced number of scalids with only 4-6 rows 
(Altenburger et al. 2015; Herranz et al. 2019; Rucci et al. 2020). However, there are also several differences regarding number and appearance of the spinoscalids among species (e.g., absence of trichoscalids in F. kalenesos, presence of hairy patches only in $C$. styx and $F$. kalenesos, or reduction of the second row of spinoscalids to fringes in Z. yong). Despite the observed differences, the musculature associated with the introvert is similar, and variation is restricted to the number of circular muscles and appearance of scalid-associated muscles. $Z$. yong has only three introvert circular muscles, whereas $F$. kalenesos shows four and $C$. styx six (Figs 2a-b; 4b, d; 5a, b; 6b) . The primary spinoscalids are very elongated and flexible in, C. styx, F. kalenesos and Z. yong, resembling tentacles or palps. However, Z. yong is the only species with intrinsic muscles in the primary spinoscalids (Fig. $2 \mathrm{~g}$ ). Interestingly, closely related genera like Antygomonas, Tubulideres and Centroderes have also been described to have intrinsic muscles, which might be a synapomorphy for kentrorhagids (Müller and Schmidt-Rhaesa 2013; Herranz et al. 2020, Herranz pers. obs.). Other cyclorhagids, such as Echinoderidae, lack intrinsic muscles in the primary spinoscalids (Herranz et al 2014), and no data is available for Xenosomata. Within Allomalorhagida, intrinsic muscles in the primary spinoscalids are only present in Dracoderes (Herranz et al. 2020).

The mouth cone is extraordinarily long in C. styx, F. kalenesos and Z. yong (Altenburger et al. 2015; Herranz et al. 2019; Rucci et al. 2020). The three species show circular musculature at the base of the inner and outer oral styles; however, only $Z$. yong shows small muscles associated with each of the outer oral styles, meaning that they have independent motility (Fig. 2g). Species of Antygomonas also have intrinsic muscles in the outer oral styles (Müller and Schmidt-Rhaesa 2013), and unpublished results also confirm their presence in other kentrorhagids such as Centroderes and Tubulideres species (Herranz pers. obs.). This again points towards a closer relationship between Cateria and Franciscideres rather than with Zelinkaderes, which shows more myoanatomical similarities with other kentrorhagids.

\section{Neck}

Among aberrant kinorhynchs the neck is the body region that shows most morphological disparity. While $C$. styx lacks a differentiated neck, its sister species $C$. gerlachi, does have a weakly developed neck with indications of placids (Neuhaus and Kegel 2015; Herranz et al. 2019). Triodontoderes species have distally tripartite and differentiated placids as extensions of the first trunk segment (Sørensen and Rho 2009). Zelinkaderes species show a weakly 
defined neck with reduced placids (e.g., Higgins 1990; Dal Zotto 2013; Altenburger et al. 2015), whereas Gracilideres and Franciscideres show a cylindrical segment-like neck without placids (Dal Zotto et al. 2013, Yamasaki 2019). This morphological plasticity has an influence on the functionality of the closing apparatus and the underlying muscles. The three studied species show a radial closing apparatus. In Z. yong and F. kalenesos the neck has associated circular musculature, showing three muscles in Z. yong and one single muscle in F. kalenesos (Figs 2b; 4d). C. styx lacks a distinct neck but shows six circular muscles situated along the introvert region and anteriormost part of segment 1 , which reduce the introvert diameter and assist in closing after the head is withdrawn into the trunk (Fig. 6b). F. kalenesos is the only species that shows longitudinal muscles in the neck. Based on their position and attachment, these muscles seem to be equivalent to the longitudinal (ventral and dorsal) muscles found in the trunk segments (Fig. 5).

Trunk

Aberrant kinorhynchs share the presence of a trunk with very thin cuticle and poorly defined segments; however, they show different segment compositions. Cateria species have segments 1-6 composed of a single tergal and sternal plate, and a single tergal plate with a midventral articulation on segments 7-11 (Neuhaus and Kegel 2015; Herranz et al. 2019). In Triodontoderes species segment 1 is composed of one tergal and one sternal plate, segments 2-4 of one tergal and two sternal plate and segments 5-11 of one tergal plate with midventral articulation (Sørensen and Rho 2009; Cepeda et al 2019). Gracilideres mawatarii Yamasaki, 2019 shows all trunk segments as a closed ring (Yamasaki 2019). F. kalenesos has segments 1 , 2 and 11 as closed cuticular rings while the remaining segments are composed of a tergal plate with weak midventral articulation (Dal Zotto et al. 2013). Z. yong has segments 1-2 as rings and the remaining segments as a tergal plate with a midventral articulation (Altenburger et al. 2015). Despite these differences the underlying trunk musculature in the three studied species does not vary much. The main differences found in the trunk musculature are related to the dorsoventral and lateral muscles. Dorsoventral muscles are present in all segments in C. styx and F. kalenesos, but lacking in segment 1 in $Z$. yong (Fig. 2a). These muscles have also been reported throughout the trunks of the allomalorhagid genera Pycnophyes and Setaphyes (Rothe and Schmidt-Rhaesa 2004; Schmidt-Rhaesa and Rothe 2006; Altenburger et al. 2015, Herranz et al. 2020). Some cyclorhagid genera, such as Echinoderes, lack dorsoventral muscles 
in segment 1 (Herranz et al. 2014), while in other genera such as Antygomonas, one species (Antygomonas sp.) was described as having dorsoventral muscles in all segments (Müller and Schmidt-Rhaesa 2003). However, unpublished material of various Antygomonas species (Herranz pers. obs.) shows a consistent absence of dorsoventral muscles in segment 1 , which would agree with the configuration found in Z. yong. This stresses the differences between $Z$. yong with C. styx and F. kalenesos.

The three studied species show lateral longitudinal muscles in most trunk segments (Figs $3 ; 5 ; 7)$. These muscles contribute to increase the flexibility of the trunk, especially allowing lateral movements and rotation. The position of the lateral muscles seems to be more oblique in C. styx and Z. yong, whereas it is more longitudinal - almost parallel to the ventromedial muscles - in F. kalenesos. Based on their position and function, the lateral muscles could be homologous with the diagonal muscles described in most cyclorhagids (Müller and Schmidt-Rhaesa 2003, Herranz et al. 2014) and Dracoderes (Herranz et al. 2020).

Trunk spines, excluding the terminal spines on segment 11 , do not seem to be associated with muscles in any kinorhynch and are therefore assumed to move passively with the trunk (Müller and Schmidt-Rhaesa 2003; Neuhaus 2013; Herranz et al 2014). This is confirmed also by the present study; however, we consistently found weak F-actin labelling forming a ring-shape in the central part of all cuspidate spines in Z. yong (Fig. 2j'). The same labelling could be observed inside the cuspidate spines of Antygomonas species (Herranz pers. obs.), suggesting a contractile capability. The presence of a terminal pore in the distal end of all cuspidate spines is congruent with their presumed secretory function (Neuhaus 2013). Thus the F-actin ring-like labeling could correspond to a sphincter that would control the opening of the glandular pore. Based on these results, it would be expected to find similar F-actin labelling in all other genera with well-developed cuspidate spines such as Semnoderes, Sphenoderes, Condyloderes or Wollunquaderes. The terminal spines are the only trunk spines with associated musculature in the three studied species; however, there are differences in number and orientation of the muscles. In Z. yong the midterminal spine is associated with two strong longitudinal muscles while in C. styx the midterminal spine has no musculature (Figs $2 \mathrm{j}^{\prime \prime} ; 6 \mathrm{~h}$ ). F. kalenesos lacks a midterminal spine but instead it has a long middorsal spine on segment 11 without associated musculature. This means that only $Z$. yong can actively move the midterminal spine and again stresses the differences from $C$. styx and $F$. kalenesos. The occurrence of muscles associated with the midterminal spine has also been described in Antygomonas sp. with positions identical with those described for Z. yong (Müller and 
Schmidt-Rhaesa 2003) which reflects their kentrorhagid affinity. Unpublished studies (Herranz pers. obs.) also confirm the presence of midterminal spine muscles in Tubulideres. Lateral terminal accessory spines always seem to be connected with levator muscles in the three studied species. Interestingly, the lateral terminal spines do not seem to have associated musculature. But nonetheless, due to their proximity, it is possible that they can indirectly move together with the lateral accessory spines as described for $F$. kalenesos.

\section{Functional morphology in aberrant kinorhynchs}

Within Kinorhyncha, there is a great variation in cuticle thickness ranging from very robust and sclerotized plates (e.g., Pycnophyes, Setaphyes, Dracoderes and Echinoderes) to extremely thin ones as in aberrant kinorhynchs (Neuhaus 2013). The only studies including ultrastructural details of cuticle composition and thickness are from different species of Pycnophyes, with a cuticle of ca. 5-5.5 $\mu \mathrm{m}$; Echinoderes, with ca. $3 \mu \mathrm{m}$; Zelinkaderes, ca. $1 \mu \mathrm{m}$ and C. styx, ca. 0.5 $\mu \mathrm{m}$ (Moritz and Storch 1972; Kristensen and Higgins 1991; Bauer-Nebelsick 1995; Hirose and Yamasaki 2015; Herranz pers. obs.). The thickness of the cuticle also varies in the different body regions where the trunk plates, and neck placids are the thickest and most rigid, and the introvert (excluding the scalids), intersegmental and interplacid areas the thinnest and most flexible (Kristensen and Higgins 1991; Bauer-Nebelsick 1995; Neuhaus 2013). In aberrant kinorhynchs the differences in cuticle thickness among body regions are not distinct. The cuticle is thin and flexible in most areas, except for the mouth cone, spinoscalid bases and trunk spines. In most kinorhynchs, trunk segments are articulated through soft, flexible, intersegmental cuticle and have anterior apodeme-like cuticular thickenings, named pachycycli, to which the muscles attach (Kristensen and Higgins 1991; Neuhaus 2013); however, aberrant kinorhynchs lack pachycycli (Bauer-Nebelsick 1995; Dal Zotto et al. 2013; Altenburger et al. 2015; Neuhaus and Kegel 2015; Yamasaki 2019). The absence of pachycycli affects the attachment points of the longitudinal muscles, which are posteriorly displaced into each segment leaving conspicuous markings, visible in the cuticle surface, named "muscle scars". In the studied species the external segmentation of the cuticle does not correlate with the segmental arrangement of the muscles, which is staggered, giving the false impression that the longitudinal muscles are continuous. The arrangement of the trunk longitudinal muscles, combined with the thin and flexible cuticle allows the trunk segments to fold. This way aberrant kinorhynchs can contract along the anterior-posterior axis further than common kinorhynchs, which have rigid segments, producing a characteristic accordion-like movement 
described for C. styx and F. kalenesos (Herranz et al. 2019, Rucci et al. 2020) (Online resource 1, 2). Accordion-like movements are combined with fast twisting and coiling in $C$. styx and $F$. kalenesos resembling a worm-like locomotion (Herranz et al. 2019, Rucci et al. 2020).

The neck in aberrant kinorhynchs is weakly developed, composed of very thin cuticle without well-differentiated placids, or even absent as in C. styx (Neuhaus and Kegel 2015; Herranz et al. 2019). Functionally, weakly developed necks do not seem to act as a closing apparatus, as they usually invert into the trunk together with the introvert (Bauer-Nebelsick 1995; Herranz et al. 2019) (Fig. 8). In C. styx, F. kalenesos and Z. yong the primary spinoscalids are so long that they cannot be fully withdrawn with the introvert, confirming that the neck does not act as a closing apparatus, as in most kinorhynchs, but just as an introvert constrictor (Herranz et al. 2019) (Fig. 8). In F. kalenesos the neck is highly modified being unusually long. Externally it resembles an additional segment, with a slightly different cuticular ornamentation (showing parallel longitudinal furrows) when compared with trunk segments (with scale-like structures). F. kalenesos' neck has a central circular muscle with associated longitudinal muscles that extend into segment 1 . These dorsal and ventral sets of longitudinal muscles might contribute to shorten the neck length during introvert withdrawal, facilitating the scalid constriction. Even though the neck in F. kalenesos is completely different from, C. styx and Z. yong it also lacks placids and can be withdrawn with the introvert as described in Z. yong. Similar to F. kalenesos, G. mawatarii shows a segment-like neck with longitudinal furrows and no placids. Due to the close relationship between Franciscideres and Gracilideres and the morphological resemblance of the neck (Sørensen et al. 2015, Yamasaki 2019), G. mawatarii is expected to have similar underlying muscles as $F$. kalenesos.

In all kinorhynchs, the mouth cone and introvert each possess particular musculature and neural elements, and they can move independently (Herranz et al. 2014, 2019). However, in most kinorhynchs due to their proximity, the mouth cone is indirectly moved together with the introvert during the eversion of the head and thus a full eversion of the introvert involves a protraction of the mouth cone (Fig. 8 a-c). Aberrant kinorhynchs have an extraordinarily long mouth cone connected with the introvert through a long and flexible cuticle (Dal Zotto et al. 2013; Neuhaus and Kegel 2015; Herranz et al. 2019; Yamasaki 2019; Rucci et al. 2020) (Fig. 8 df). This way, the mouth cone and introvert are physically more separated from each other (e.g., ca. $100 \mu \mathrm{m}$ distance from the base of the mouth cone to the introvert spinoscalids in $C$. styx), and the introvert can be completely extended while the mouth cone is still fully retracted into the trunk (e.g., Online resources 1-2). Live observations of $F$. kalenesos show the 
mouth cone being rapidly protruded and retracted independent from the introvert, confirming this interpretation (Rucci et al. 2020). We could not find mouth cone protractor muscles in $F$. kalenesos therefore, this fast movement is presumed to be produced by increased internal pressure from the fast contraction of dorsoventral muscles of the trunk. Movement of the elongated outer oral styles in C. styx and F. kalenesos is controlled by a single circular muscle that opens and closes the styles in synchrony as demonstrated by Rucci et al. (2020). Each outer oral style in $Z$. yong has, besides the circular muscles, associated longitudinal muscles which might provide additional motility.

Kinorhynch introverts are locomotory and sensorial apparatuses (Kristensen and Higgins 1991; Neuhaus 2013; Herranz et al. 2014, 2019, 2020). Locomotion in the absence of limbs is mostly carried out through the eversion, anchoring to the substrate and withdrawal of the introvert, with help of the contraction/extension of the trunk. As a result, the animal is pulled forward through the sediment (Neuhaus 2013, Herranz et al. 2014). The introvert in aberrant kinorhynchs shows multiple modifications, including the reduction in number and elongation of the spinoscalids. This is most conspicuous in the primary spinoscalids which are tentacle-like. Flexible and elongated spinoscalids as present in aberrant kinorhynchs might be less efficient for a lever-based locomotion, suggesting a more sensory and less locomotory function of the introvert. The thin and flexible cuticle of the trunk combined with the elongation and contraction of the trunk segments seem to produce the characteristic, wormlike, movement most likely responsible of the forward locomotion in aberrant kinorhynchs (see Additional files in Rucci et al. 2020).

\section{Are aberrant kinorhynchs adapted to the interstitial environment?}

It is broadly known that some of the adaptations shown by interstitial fauna are related with flexible, elongated and slender body shapes (Giere 2009). Tendencies towards vermiformity in interstitial organisms have been clearly described compared with the same organisms from different biotopes (e.g. nemerteans, nematodes, copepods, ostracods, polychaetes) (Remane 1933; Swedmark 1964; Giere 2009). Most aberrant kinorhynchs have been found associated with medium to coarse sandy sediments (Higgins 1968; Dal Zotto et al. 2013; Altenburger et al. 2015; Neuhaus and Kegel 2015; Herranz et al. 2019; Lopes Mello et al. 2019; Rucci et al. 2020; Yamasaki 2019) with some exceptions such as Zelinkaderes floridensis Higgins, 1990, that is found in mud (Higgins 1990). The length-to-width ratio in aberrant kinorhynchs is at least twice 
as much as in other kinorhynchs. C. styx, Z. yong, F. kalenesos and G. mawatarii show ratios above 10:1 compared with e.g.: Pycnophyes, Paracentrophyes, Dracoderes and Condyloderes ranging from 3-4:1; Echinoderes, 4-5:1 and Tubulideres, Sphenoderes 6:1 (data obtained from Sørensen et al. 2012; Dal Zotto et al. 2013; Neuhaus and Kegel 2015; Sørensen and Landers 2017; Herranz et al. 2018, 2019; Rucci et al. 2020; and others). These ratios are approximate due to the variability in the level of contraction or extension of the trunk but still show a clear difference in the proportions between aberrant and common kinorhynchs. The combination of a slender, vermiform body and a flexible cuticle should be regarded an adaptation to life in interstitial habitats (Giere 2009; Yamasaki 2019). The current phylogenetic positions of wormlike kinorhynchs, nested in distantly related clades of the tree (see Sørensen et al. 2015), suggest that their characteristic vermiform appearance evolved convergently, most likely driven by an ecological shift in niches from muddy sediments to sandy interstitial environments. However, it is important to stress that not all interstitial kinorhynchs show elongated trunks and thin cuticle, which is the case for several species of interstitial Echinoderes and Cephalorhyncha (see Higgins 1986; Sørensen 2008; Sánchez et al. 2012; Yildiz et al. 2016).

\section{Conclusions}

This study shows that a body plan with segmentally arranged musculature remains conserved across Kinorhyncha, both morphologically and functionally. Despite their vermiform appearance, aberrant kinorhynchs have segmentally arranged musculature. However, differing from most kinorhynchs, where longitudinal muscles attach to the pachycycli situated at the anterior segment margins, the muscles of aberrant kinorhynchs attach more posteriorly. The attachment points for the longitudinal muscles in the trunk of aberrant kinorhynchs are instead displaced to the anteriormost part, or the central part, of each tegumental plate. The lack of pachycycli is associated with the extremely thin and flexible cuticle characteristic of the worm-like kinorhynchs.

Morphologically and myoanatomically, C. styx shows more resemblance with $F$. kalenesos, than it does with $Z$. yong. This suggests that Cateria is more closely related to allomalorhagids than to cyclorhagids. The distant phylogenetic positions of Zelinkaderes and Franciscideres (and possibly Cateria) suggest that the aberrant appearance evolved at least 
Pre-print. The final authenticated version is available on-line at: https://link.springer.com/article/10.1007/s00435-021-00519-3

twice independently, and that it most likely reflects an adaptation to the interstitial environment. 


\section{References}

Altenburger A, Rho HS, Chang CY, Sørensen MV (2015) Zelinkaderes yong sp. nov. from Korea the first recording of Zelinkaderes (Kinorhyncha: Cyclorhagida) in Asia. Zool Stud 54:25. http://dx.doi.org/10.1186/s40555-014-0103-6

Altenburger A (2016) The neuromuscular system of Pycnophyes kielensis (Kinorhyncha: Allomalorhagida) investigated by confocal laser scanning microscopy. EvoDevo 7(1) 25. https://doi.org/10.1186/s13227-016-0062-6

Bauer-Nebelsick M (1995) Zelinkaderes klepali sp. n., from shallow water sands of the Red Sea. Ann Nat Mus Wien 97B:57-74

Cepeda D, Sánchez N, Pardos F (2019) First report of the family Zelinkaderidae (Kinorhyncha: Cyclorhagida) for the Caribbean Sea, with the description of a new species of Triodontoderes Sørensen \& Rho, 2009 and an identification key for the family. Zool Anz 282:116-126. https://doi.org/10.1016/j.jcz.2019.05.017

Dal Zotto M, Di Domenico M, Garraffoni A, Sørensen MV (2013) Franciscideres gen. nov. - a new, highly aberrant kinorhynch genus from Brazil, with an analysis of its phylogenetic position. Syst Biodivers 11:303-321. http://dx.doi.org/10.1080/14772000.2013.819045

Gerlach SA (1956) Über einen aberranten Vertreter der Kinorhynchen aus dem Küstengrundwasser. Kieler Meeresforsch. 12:120-124

Gerlach SA (1969) Cateria submersa sp.n., ein cryptorhager Kinorhynch aus dem sublitoralen Mesopsammal der Nordsee. Veröff. Inst. Meeresforsch. Bremerh. 12:161-168

Giere O (2009) Meiobenthology. The Microscopic Motile Fauna of Aquatic Sediments, second ed. Springer-Verlag Berlin, Heidelberg.

Herranz M, Boyle M, Pardos F, Neves RC (2014) Comparative myoanatomy of Echinoderes (Kinorhyncha): a comprehensive investigation by CLSM and 3D reconstruction. Frontiers in Zool 11:1-26. https://doi.org/10.1186/1742-9994-11-31

Herranz M, Di Domenico M, Sørensen MV, Leander BS (2019) The enigmatic kinorhynch Cateria styx Gerlach, 1956 - A sticky son of a beach. Zool Anz 282:10-30 https://doi.org/10.1016/j.jcz.2019.05.016

Herranz M, Pardos F, Boyle M (2013). Comparative morphology of serotonergic-like immunoreactive elements in the central nervous system of kinorhynchs (Kinorhyncha, Cyclorhagida). J Morphol 274:258-74. https://doi.org/10.1002/jmor.20089

Herranz M, Sørensen MV, Park T, Leander BS, Worsaae K (2020). Insights into mud dragon morphology (Kinorhyncha, Allomalorhagida): myoanatomy and neuroanatomy of Dracoderes abei and Pycnophyes ilyocryptus. Org Divers Evol 20:467-493. https://doi.org/10.1007/s13127$\underline{020-00451-2}$

Herranz M, Yangel E, Leander BS (2018) Echinoderes hakaiensis sp. nov.: a new mud dragon (Kinorhyncha, Echinoderidae) from the northeastern Pacific Ocean with the redescription of Echinoderes pennaki Higgins, 1960. Mar Biodiv 48, 303-325 http://dx.doi.org/10.1007/s12526017-0726-z 
Higgins RP (1968) Taxonomy and postembryonic development of the Cryptorhagae, a new suborder for the mesopsammic kinorhynch genus Cateria. Trans Amer Microsc Soc 87:21-39 Higgins RP (1986) A new species of Echinoderes (Kinorhyncha: Cyclorhagida) from a coarsesand California beach. Trans Am Microsc Soc 105: 266-273

Higgins RP (1990) Zelinkaderidae, a new family of cyclorhagid Kinorhyncha. Smithson Contr Zool 500:1-26

Hirose $\mathrm{E}$, Yamasaki H (2015) Fine structure of the integumentary cuticles and alimentary tissues of pycnophyid kinorhynchs Pycnophyes oshoroensis and Kinorhynchus yushini (Kinorhyncha, Homalorhagida). Zool Sci 32:389-395. https://doi.org/10.2108/zs150021 Kristensen RM, Higgins RP (1991) Kinorhyncha. In: Microscopic anatomy of invertebrates, Vol. 4, The Aschelminthes, Harrison FW, Ruppert EE (ed). Wiley-Liss, New York, pp 377-404 Lopes Mello C, Carvalho AL, Cabral de Faria L, Baldoni L, Di Domenico M (2019) Spatial distribution pattern of the aberrant Franciscideres kalenesos (Kinorhyncha) on sandy beaches of Southern Brazil. Zool Anz 282:44-51 https://doi.org/10.1016/j.jcz.2019.05.008

Moritz K, Storch V (1972) Zur Feinstruktur des Integumentes von Trachydemus giganteus (Kinorhyncha). Z Morphol Tiere 71:189-202

Müller MCM, Schmidt-Rhaesa A (2003) Reconstruction of the muscle system in Antygomonas sp. (Kinorhyncha, Cyclorhagida) by means of phalloidin labeling and CLSM. J Morphol 256:103110. https://doi.org/10.1002/jmor.10058

Nebelsick (1993) Introvert, mouth cone, and nervous system of Echinoderes capitatus (Kinorhyncha, Cyclorhagida) and implications for the phylogenetic relationships of Kinorhyncha. Zoomorphology 113: 211-232. https://doi.org/10.1007/BF00403313

Neuhaus B (1994) Ultrastructure of alimentary canal and body cavity, ground pattern, and phylogenetic relationships of the Kinorhyncha. Microfauna Mar 9: 61-156

Neuhaus B, Kegel A (2015) Redescription of Cateria gerlachi (Kinorhyncha, Cyclorhagida) from Sri Lanka and of $C$. styx from Brazil, with notes on C. gerlachi from India and C. styx from Chile, and the ground pattern of the genus. Zootaxa 3965:1-77.

https://doi.org/10.11646/zootaxa.3965.1.1

Remane A (1933) Verteilung und Organisation der benthonischen Mikrofauna der Kieler. Bucht Wiss Meeresuntersuch 21, 161-221.

Rucci KA, Neuhaus B, Bulnes VN, Cazzaniga NJ (2020). New record of the soft-bodied genus Franciscideres (Kinorhyncha) from Argentina, with notes on its movement and morphological variation. Zootaxa 4780:107-131. https://doi.org/10.11646/zootaxa.4780.1.5

Schmidt-Rhaesa A, Rothe B (2006) Postembryonic development of dorsoventral and longitudinal musculature in Pycnophyes kielensis (Kinorhyncha, Homalorhagida). Integr Comp Biol 46:144-50. https://doi.org/10.1093/icb/icj019 
Sánchez N, Herranz M, Benito J, Pardos F (2012) Kinorhyncha from the Iberian Peninsula: new data from the first intensive sampling campaigns. Zootaxa 3402: 24-44.

https://doi.org/10.11646/zootaxa.3402.1.2

Sørensen MV (2008) A new kinorhynch genus from the Antarctic deep-sea and a new species of Cephalorhyncha from Hawaii (Kinorhyncha: Cyclorhagida: Echinoderidae). Org Div Evol 8: 233-246. http://dx.doi.org/10.1016/j.ode.2007.11.003

Sørensen MV, Dal Zotto M, Rho HS, Herranz M, Sánchez N, Pardos F, Yamasaki H (2015) Phylogeny of Kinorhyncha based on morphology and two molecular loci. PLoS ONE 10(7): e0133440. http://dx.doi.org/10.1371/journal.pone.0133440

Sørensen MV, Herranz M, Rho HS, Min W, Yamasaki H, Sánchez N, Pardos F (2012) On the genus Dracoderes Higgins \& Shirayama, 1990 (Kinorhyncha: Cyclorhagida) with a redescription of its type species, D. abei, and a description of a new species from Spain. Mar Biol Res 8: 210232. https://doi.org/10.1080/17451000.2011.615328

Sørensen MV, Landers SC (2017) Description of a new species, Paracentrophyes sanchezae $\mathrm{n}$. sp. (Kinorhyncha: Allomalorhagida) from the Gulf of Mexico, with differential notes on one additional, yet undescribed species of the genus. Zootaxa 4242: 61-76.

http://dx.doi.org/10.11646/zootaxa.4242.1.3

Sørensen MV, Pardos F (2020) Kinorhyncha. In: Schmidt-Rhaesa A (ed) Guide to the Identification of Marine Meiofauna. Verlag Dr. Friedrich Pfeil, Munich, pp. 391-414

Sørensen MV, Rho HS (2009). Triodontoderes anulap gen. et sp. nov. - A new cyclorhagid kinorhynch genus and species from Micronesia. J Mar Biol Assoc UK 89, 1269-1279. http://dx.doi.org/10.1017/S0025315409000526

Swedmark B (1963) The interstitial fauna of marine sand. Biol Rev 39, 1-42.

Yamasaki H (2019) Gracilideres mawatarii, a new genus and species of Franciscideridae (Allomalorhagida: Kinorhyncha) - A kinorhynch with thin body cuticle, adapted to the interstitial environment. Zool Anz 282:176-88. https://doi.org/10.1016/i.jcz.2019.05.010 Yamasaki H, Hiruta SF, Kajihara H (2013) Molecular phylogeny of kinorhynchs. Mol Phylogenet Evolut 67:303-310. http://dx.doi.org/10.1016/j.ympev.2013.02.016

Yildiz NÖ, Sørensen MV, Karaytuğ S (2016) A new species of Cephalorhyncha Adrianov, 1999 (Kinorhyncha: Cyclorhagida) from the Aegean Coast of Turkey. Helgol Mar Res 70: 24. http://dx.doi.org/10.1186/s10152-016-0476-5 


\section{Figure captions}

Fig. 1 External anatomy of Cateria styx, Franciscideres kalenesos and Zelinkaderes yong. Scanning electron micrographs. All views with anterior to the top and dorsal to the left. a Lateral view of $C$. styx, with the introvert everted, mouth cone retracted, dorsal organ extended. $\mathbf{b}$ Detail of $C$. styx introvert, notice the very elongated primary spinoscalids. $\mathbf{c}$ Lateral view of $Z$. yong, with the introvert and mouth cone fully extended. $\mathbf{d}$ Lateroventral view of $F$. kalenesos, head retracted. Abbreviations: $h$, head; i, introvert; mc, mouth cone; $n$, neck; oos, outer oral styles; psp, primary spinoscalids; s1, segment 1 ; $t$, trunk.

Fig. 2 Myoanatomy in Zelinkaderes yong. Z-stack projections of specimens labelled with phalloidin (a-h) and scanning electron micrograph of the cuticle showing marks of muscle attachments (i). Autofluorescence of the cuticle was kept for guidance in $(g, h, j)$. Muscles of interest have been coloured in some panels according to the legend, which applies to all panels. Anterior is up in $(a, f-j)$, dorsal is up in (b-e). a Lateral view showing a $z$-stack of the right side of the specimen. $\mathbf{b}$-e Cross sections at different levels of the neck and trunk; levels of sections indicated by dashed lines and arrows in (a). $\mathbf{f - g}$ Neck and segments 1-5, head retracted, ventral view; (f) shows muscles associated with the trunk, (g) shows muscles associated with the introvert, mouth cone and pharynx. $\mathbf{h}$ Segments 1-5, dorsal view. Dashed lines mark the insertion points of longitudinal trunk muscles. i Cuticular details of segments 1 5 , dorsal view. Asterisks mark the position of the muscle scars (seen as depressions) left by the muscle attachments in the cuticle. Note how the number of depressions fits with the number of longitudinal muscle bundles in (h). j Segments 7-11 ventral view. j' Detail of the dashed square marked on $\mathrm{j}$ showing phalloidin labelling in the cuspidate spines (arrowhead). j" Detail of segments 10-11 marked in (j) with a dashed square showing muscles associated with the terminal spines. Arrowheads mark attachment points of the longitudinal trunk muscles. Note that the segmental muscle attachment points are not coincident with the intersegmental areas. Numbers refer to segments. Scale bars: $20 \mu \mathrm{m}$ (a-c, f-h), $10 \mu \mathrm{m}$ (d, e, i, j, j"), $5 \mu \mathrm{m}$ (j'). Additional abbreviations: cus, cuspidate spine; gg, gut grid; hc, hindgut constrictor; Itas, lateral terminal accessory spine; $\mathrm{mt}$, midterminal spine.

Fig. 3 Three-dimensional reconstruction of the myoanatomy in Zelinkaderes yong.

Autofluorescence of the cuticle was kept for guidance in (a-e). Anterior is up in (a-d, f-g), dorsal is up in (e). Colour legend applies to all panels. a Ventral overview. b Dorsal overview. c-d Segments 1-5, ventral and lateral views respectively. Dashed lines mark segment limits, arrowheads mark the attachment points of longitudinal muscles. e Segments 1-5, apical-lateral view. f Segments 1-5 apical-ventral view. g Segments 1-3, dorsal view. Scale bars: $50 \mu \mathrm{m}(a-b)$, $20 \mu \mathrm{m}(\mathrm{c}-\mathrm{g})$.

Fig. 4 Myoanatomy in Franciscideres kalenesos. Z-stack projections of specimens labelled with phalloidin ( $a-d, g-h)$, and scanning electron micrographs of the cuticle showing muscle attachment marks (e-f). Autofluorescence of the cuticle was kept for guidance in (a, c, g-h). Muscles of interest have been coloured in some panels according to the legend, which applies to all panels. Anterior is up in (a, c, e-h), dorsal is up in (b, d). a Detail of neck and partially open introvert, lateral view. b Apical view showing neck, introvert withdrawn. c Muscles associated with the mouth cone and pharynx, lateral view. $\mathbf{d}$ Lateral overview, head partially 
everted. e Detail of the neck, dorsal view, ( $\left.e^{\prime}\right)$ close up of muscular scar. $\mathbf{f}$ Detail of sternal plate, segment 3. Chevrons mark the muscular scar of a pharynx retractor; the arrow marks the elongated muscular scar from the dorsoventral muscles. Dashed circles mark muscular scars in (e-f). $g$ Detail of trunk musculature on segments 5-7, lateral view. Dashed lines mark segment limits. Arrowheads mark the attachment points of the longitudinal muscles. Note that the segmental muscle attachments do not coincide with the intersegmental areas. $\mathbf{h}$ Detail of segments 10-11, dorsal view. Numbers refer to segments. Scale bars: $20 \mu \mathrm{m}$ (a-d, g), $10 \mu \mathrm{m}$ (e$\mathrm{f}, \mathrm{h})$. Additional abbreviations: gg, gut grid; i, introvert; Its, lateral terminal spine; Itas, lateral terminal accessory spine; $n$, neck; $t$, trunk.

Fig. 5 Three-dimensional reconstruction of the myoanatomy in Franciscideres kalenesos. Autofluorescence of the cuticle was kept for guidance in all images, anterior is up and dorsal is to the left in all panels. Colour legend applies to all panels. a Detail of neck and segment 1 , lateral view, head retracted. $\mathbf{b}$ Detail of partially everted introvert and segment 1 , lateral view. c-e Head and trunk associated musculature, lateral view, head retracted. Arrowheads in (a, c) mark attachment points of the longitudinal muscles. Segments marked by brackets in (a-b), dashed lines mark segment limits in (c). Note that the muscle attachment points are not coincident with the intersegmental areas. Numbers refer to segments. Scale bars: $20 \mu \mathrm{m}(a-b)$, $50 \mu \mathrm{m}(\mathrm{c}-\mathrm{d})$.

Fig. 6 Myoanatomy in Cateria styx. Z-stack projections of specimens labelled with phalloidin (a$e, h-j$ ), and scanning electron micrographs of the cuticle showing muscle attachment marks ( $f-$ g). Autofluorescence of the cuticle was kept for guidance in ( $a-b, e, h-j)$. Muscles of interest have been coloured according to the legend, which applies to all panels. Anterior is up in ( $a-b$, e-h, j), dorsal is up in (c, d, i). a Lateral overview, head completely retracted. Note that the lateral muscles are broken on segment 5 . b Detail of introvert-associated muscles, head completely retracted in the trunk. c-d Cross sections at two different levels in (b) indicated by dashed lines and arrows. $\mathbf{e}$ Detail of mouth cone and pharynx associated muscles. $\mathbf{f}$ Detail of cuticle of segment 1 , ventral view, introvert partly extended. f' Close-up of dashed rectangle marked in (f) showing muscular scars of: dorsoventral muscle (dashed circle) and longitudinal muscles (arrows). $\mathbf{g}$ Detail of cuticle of segment 5 , lateral view. Chevrons mark conspicuous muscular scars from the attachments of the longitudinal muscles of the trunk; a dashed circle marks the midlateral attachment point of the dorsoventral muscle. $\mathbf{h}$ Segments 7-11 ventral view, male. i Cross section at segment 9 indicated with a dashed line and arrow in (h). Arrows mark the position of unidentified F-actin labelling. j Detail of segments 9-11 from (h), unidentified F-actin labelling marked with a dashed circle. Arrowheads in (b) and (h) mark the attachment points of the longitudinal muscles of the trunk. Numbers refer to segments. Scale bars: $20 \mu \mathrm{m}$ (a-e), $10 \mu \mathrm{m}(\mathrm{f}-\mathrm{j}), 5 \mu \mathrm{m}$ in (f').

Fig. 7 Three-dimensional reconstruction of the myoanatomy in Cateria styx. Autofluorescence of the cuticle was kept for guidance in $(a, b, d)$. Anterior is up in (b-d), right in (a) and down in (e). Colour legend applies to all panels. a Lateral view. Dashed lines mark segment limits, arrowheads mark the attachment points of longitudinal muscles. b Ventrolateral view. c Detail of closing apparatus, apical view. $\mathbf{d}$-e Laterodorsal views, right side (d), left side (e). Scale bars: $20 \mu \mathrm{m}(\mathrm{a}-\mathrm{b}, \mathrm{d}-\mathrm{e}), 10 \mu \mathrm{m}$ (c). 
Fig. 8 Schematic showing muscle function during introvert retraction in non-aberrant (a-c, modified from Herranz et al. 2014) vs aberrant (d-f) kinorhynchs. Only the muscle groups considered to be directly associated with the introvert retraction are represented. Anterior is up. Arrows indicate directional movements of the introvert scalids, mouth cone and neck. Relaxed muscles are represented with thin lines while contracted muscles are represented with thick lines. The diameter of the circular muscles also represents the level of contraction. a, e Introvert fully everted, mouth cone protruded. b, e Introvert and mouth cone partially retracted. c, $f$ Introvert and mouth cone fully retracted. Dashed lines in (d-f) represent the neck, which is lacking in some aberrant kinorhynchs (e.g. C. styx). Note that in (f) the neck is withdrawn with the introvert into the trunk while the distal end of the primary spinoscalids is left outside.

\section{Online resources}

Online resource 1. Movie showing $F$. kalenesos movement.

Online resource 2. Movie showing $C$. styx movement. 
a

b

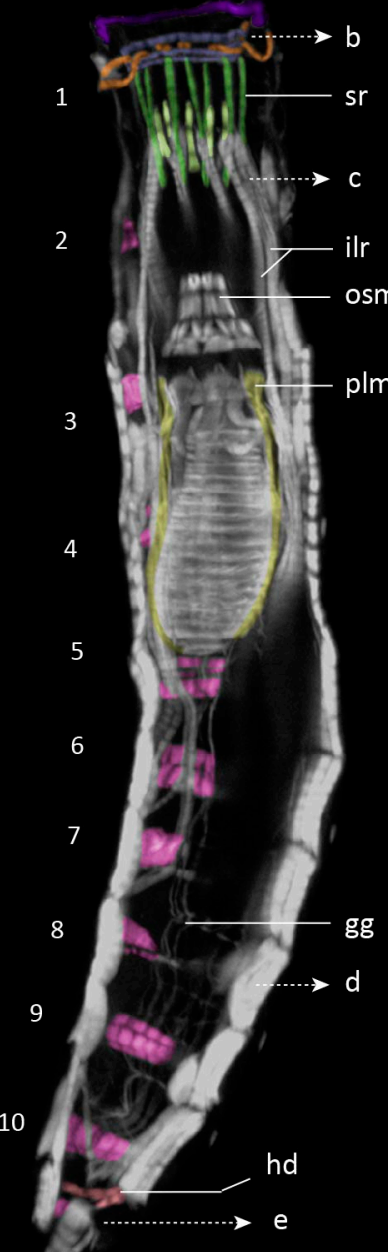

11

C
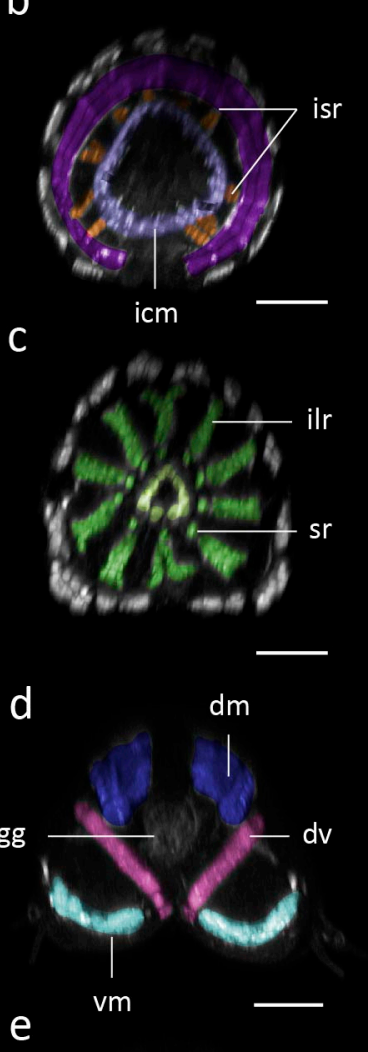

j

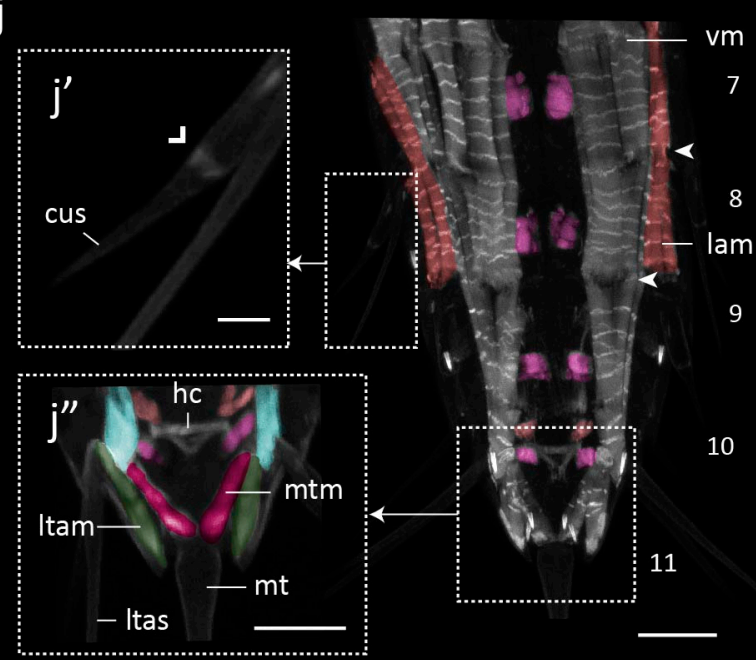

$\mathrm{nm}-$

$\mathrm{nm}$
1[

2[

3
[

4

L
5 5

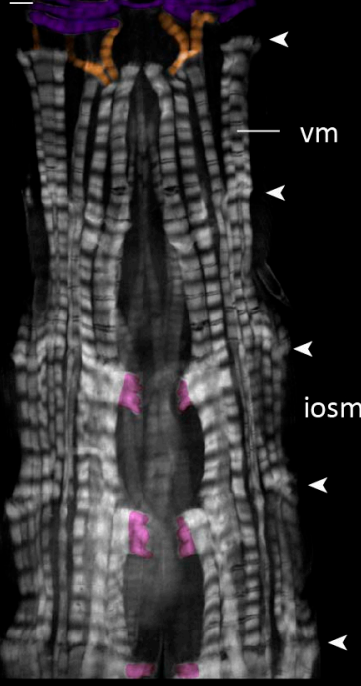

g

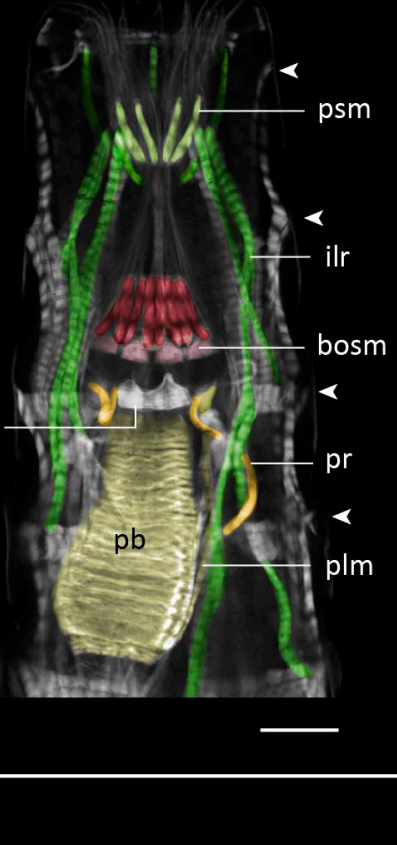

h

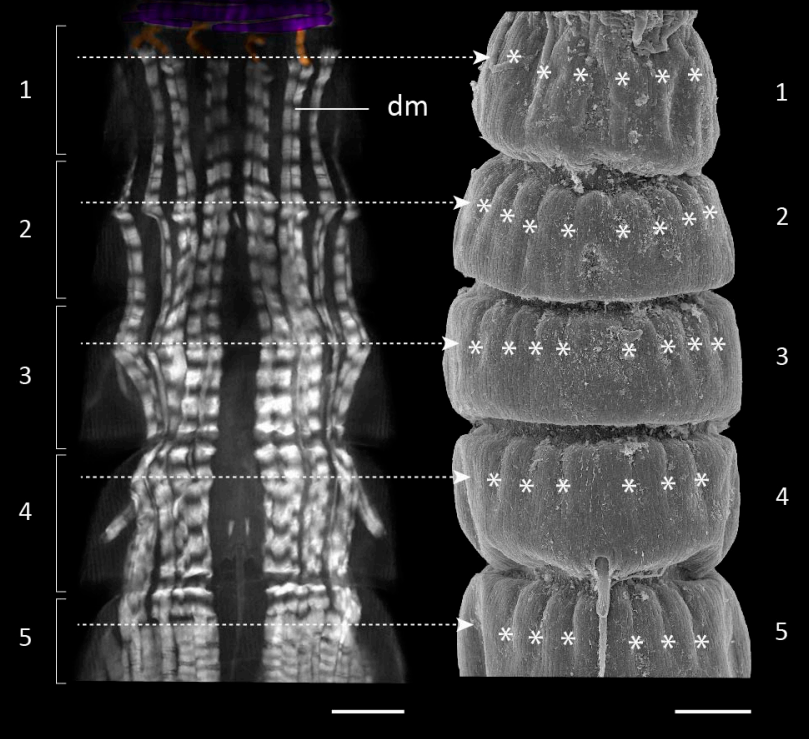

Introvert circular muscles (icm)

Neck muscles (nm)

Introvert long/spinosc. retractors (ilr/sr)

- Primary spinoscalid muscles (psm)

- Pharynx bulb (pb)/long. muscles (plm)

- Pharynx retractor muscles (pr)

- Inner oral styles muscles (iosm)

- Basal outer oral style muscles (bosm)

- Introvert short retractors (isr)

Outer oral style muscles (osm)

- Midterminal spine muscles $(\mathrm{mtm})$
Lateral muscles (lam)

Dorsoventral muscles (dv)

Ventral longitudinal muscles (vm) Dorsal longitudinal muscles (dm)

- Hindgut dilators (hd) Lateral terminal accessory spine muscles (Itam) 
a

b

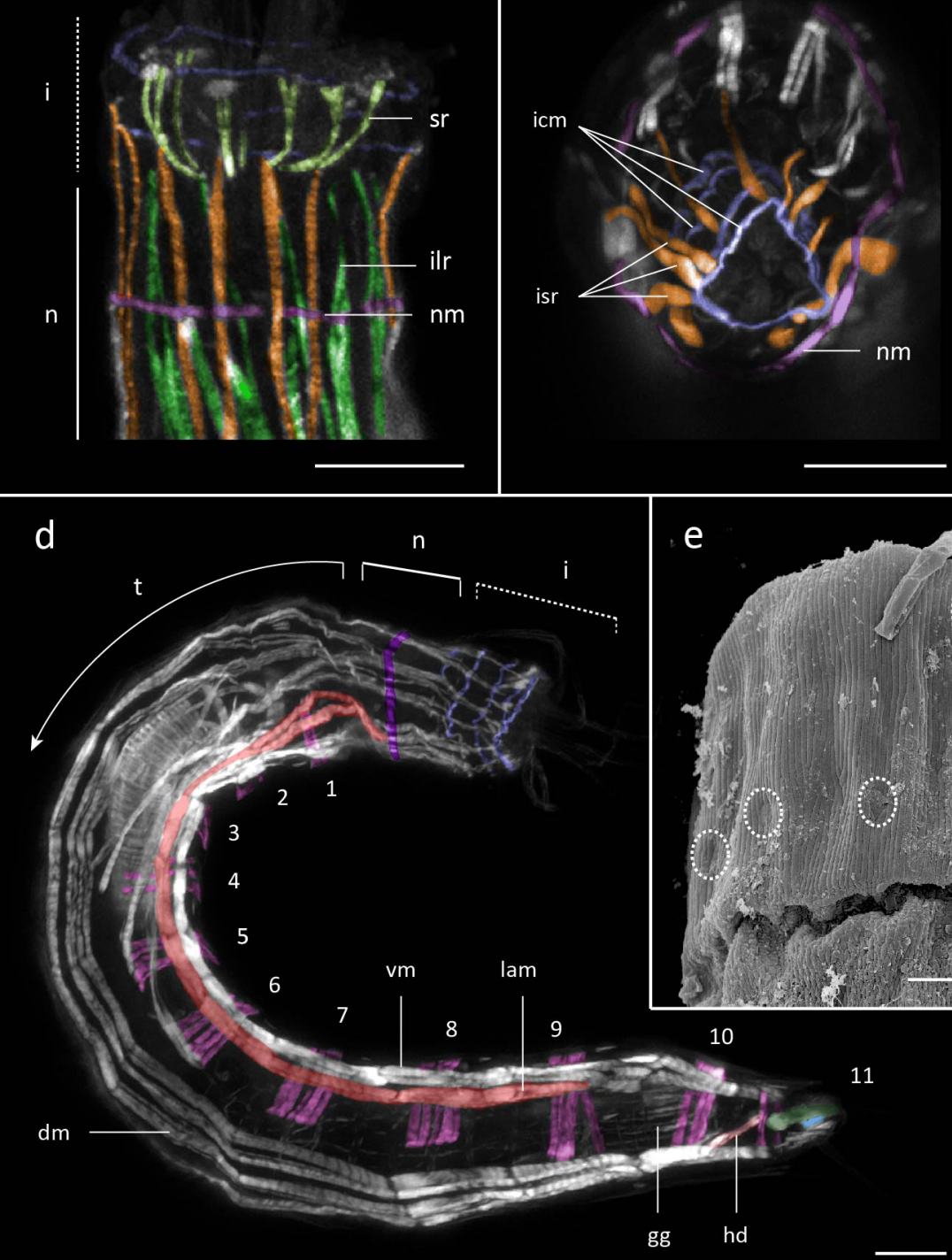

\section{g}

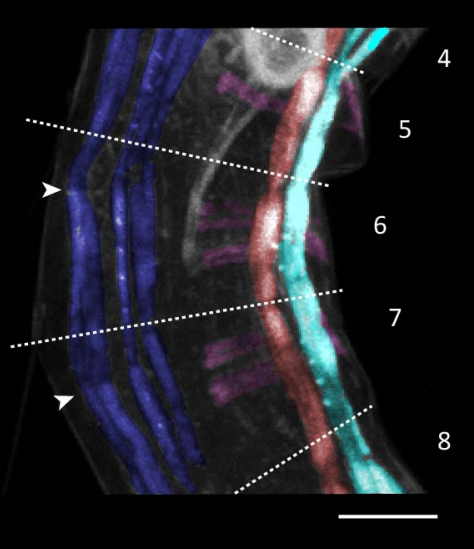

C

mcc

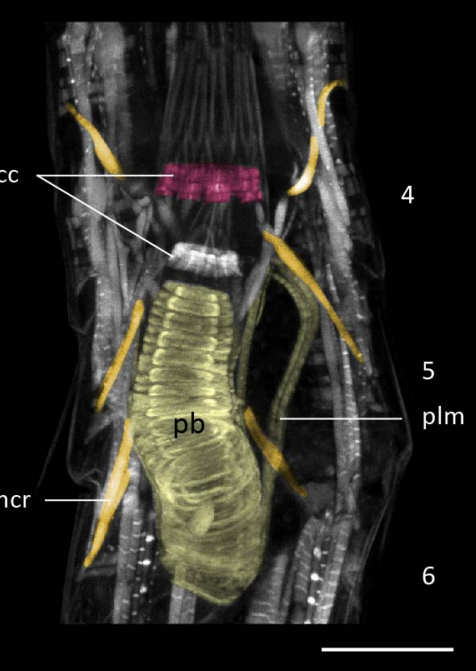


a

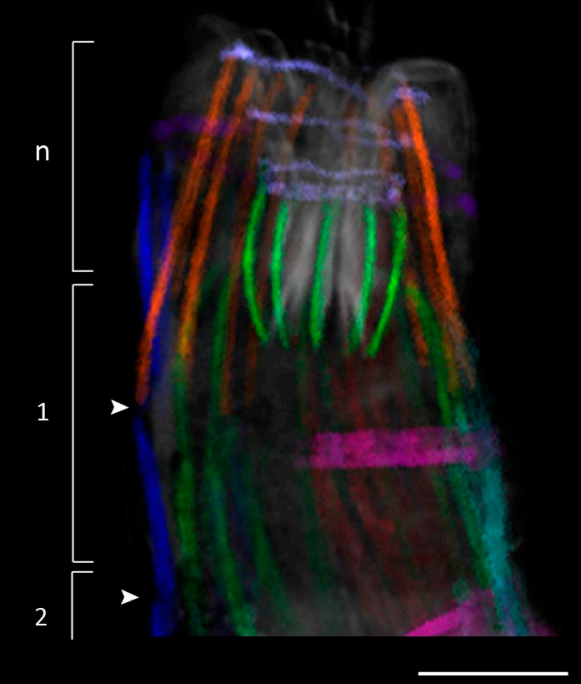

b

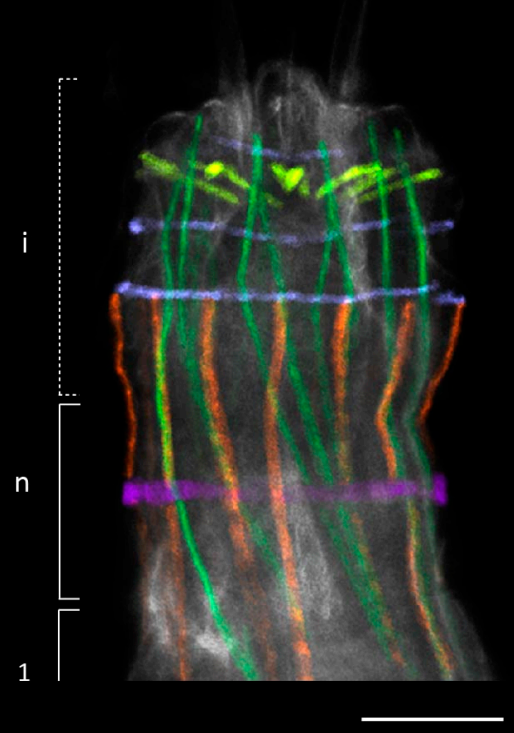

Neck muscle

- Introvert circular muscles

- Introvert short retractors

- Spinoscalid retractors

- Introvert long retractors

- Mouth cone retractors

- Pharyngeal bulb/ Pharynx longitudinal muscles

Mouth cone circular muscles

Lateral muscles

- Dorsoventral muscles

- Ventral longitudinal muscles Dorsal longitudinal muscles Lateral terminal accessory spine muscles

Transverse muscle
C

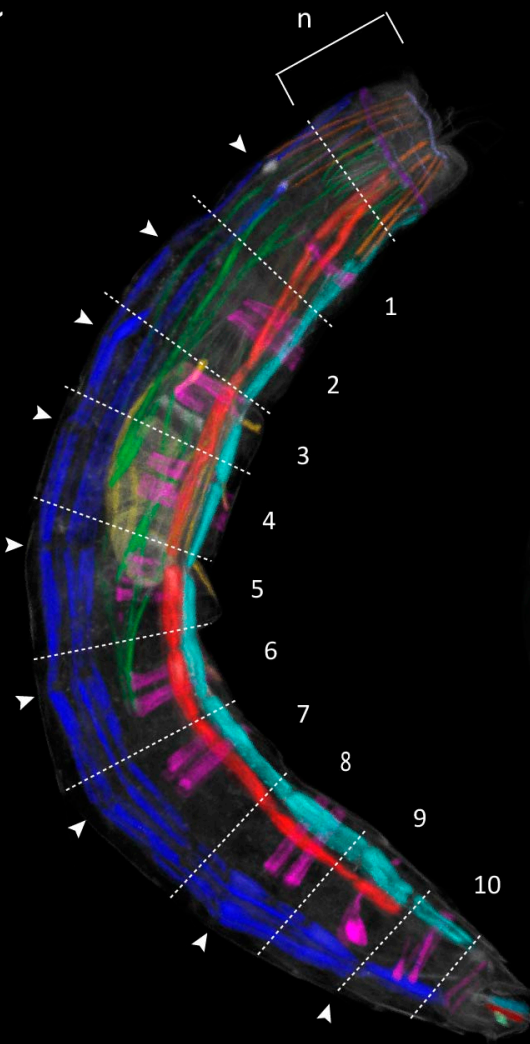

d

e 


\section{a}

11

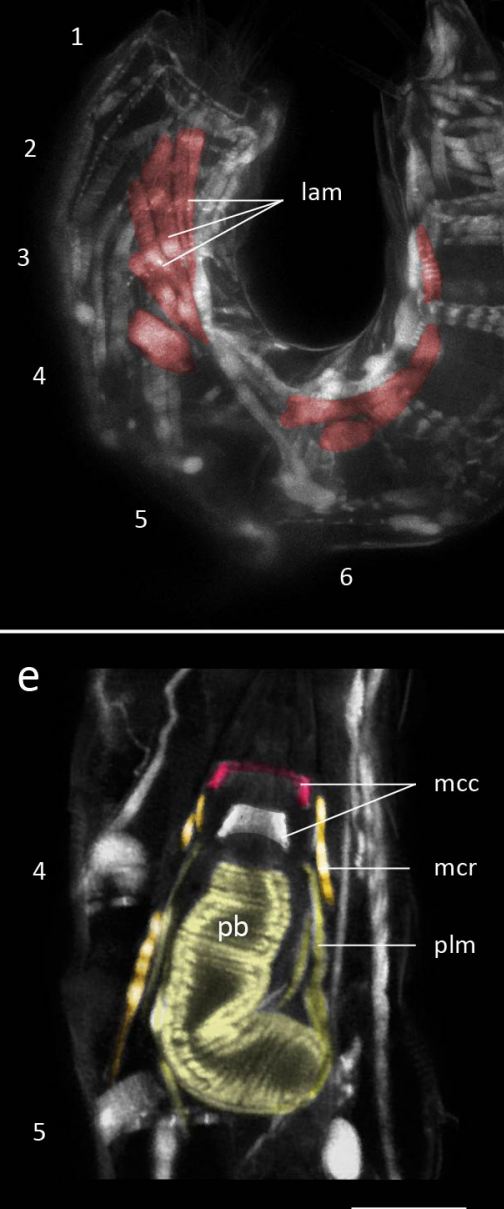

10
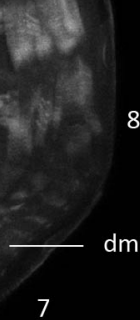

h
7

8

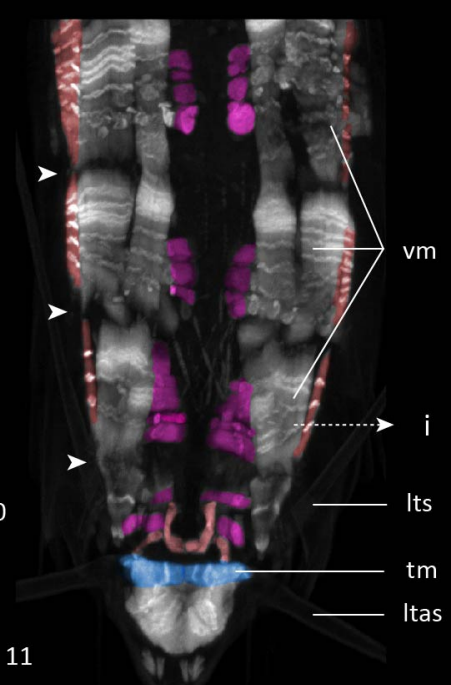

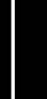

b

C

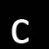

d
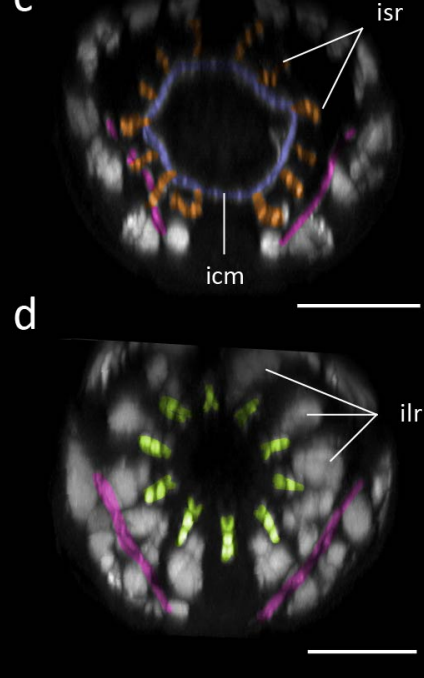

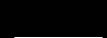

2

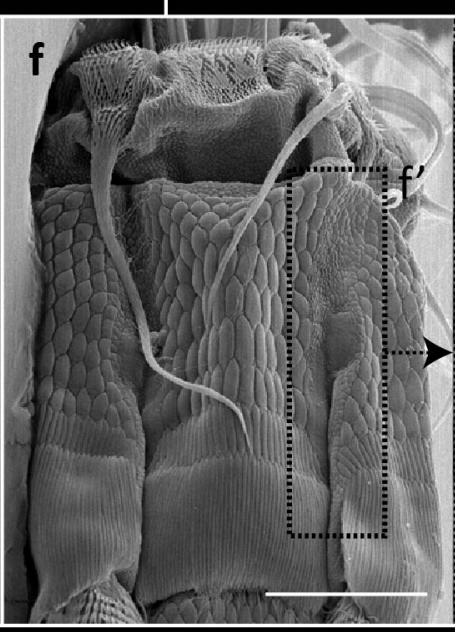

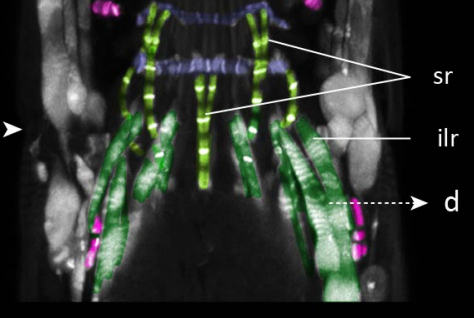

2
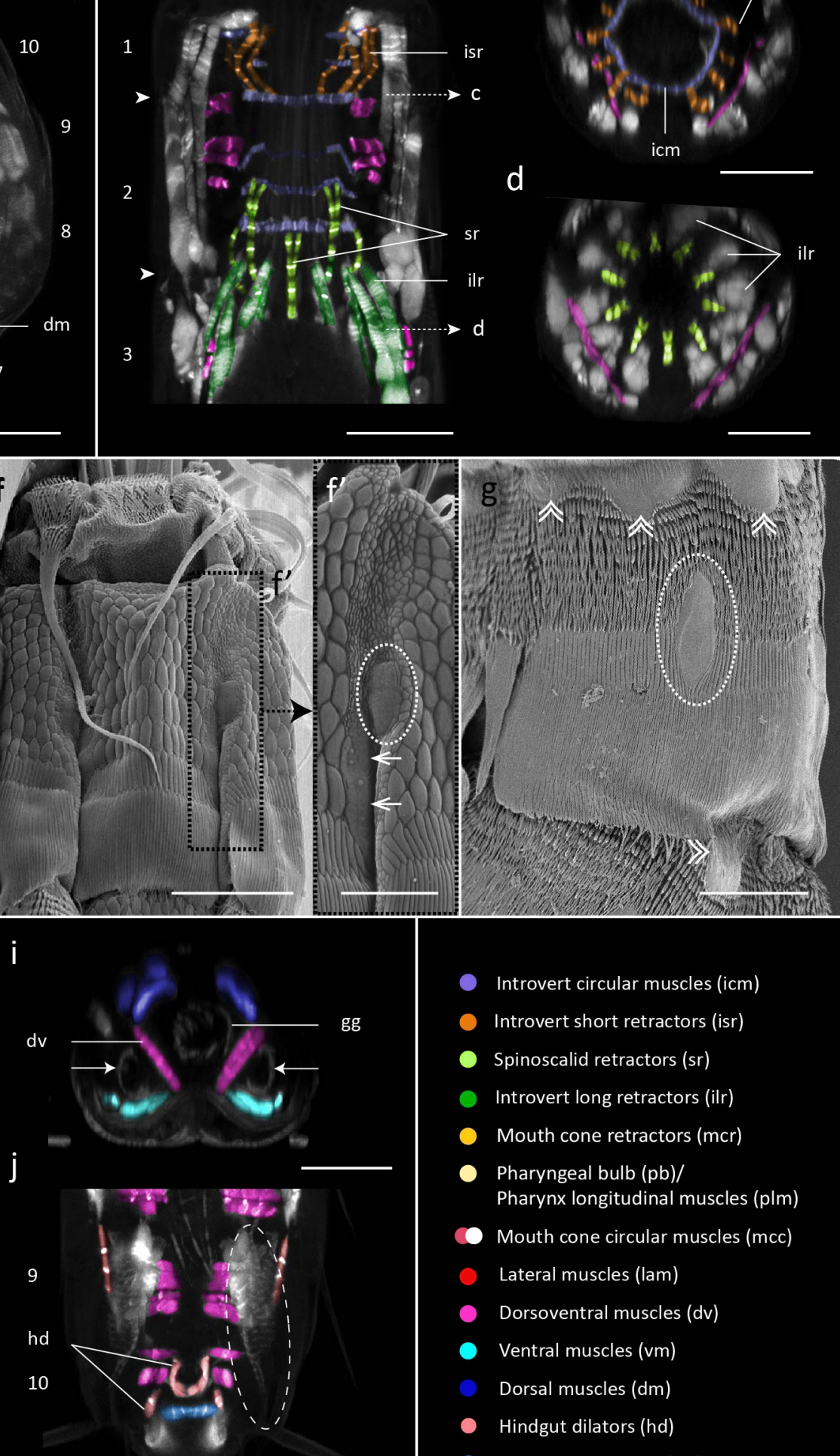

Introvert circular muscles (icm)

- Introvert short retractors (isr)

- Spinoscalid retractors (sr)

- Introvert long retractors (ilr)

Mouth cone retractors (mcr)

- Pharyngeal bulb (pb)/ Pharynx longitudinal muscles (p/m)

Mouth cone circular muscles (mcc)

Lateral muscles (lam)

Dorsoventral muscles (dv)

- Ventral muscles (vm)

Dorsal muscles (dm)

- Hindgut dilators (hd)

- Transverse muscles (tm) 


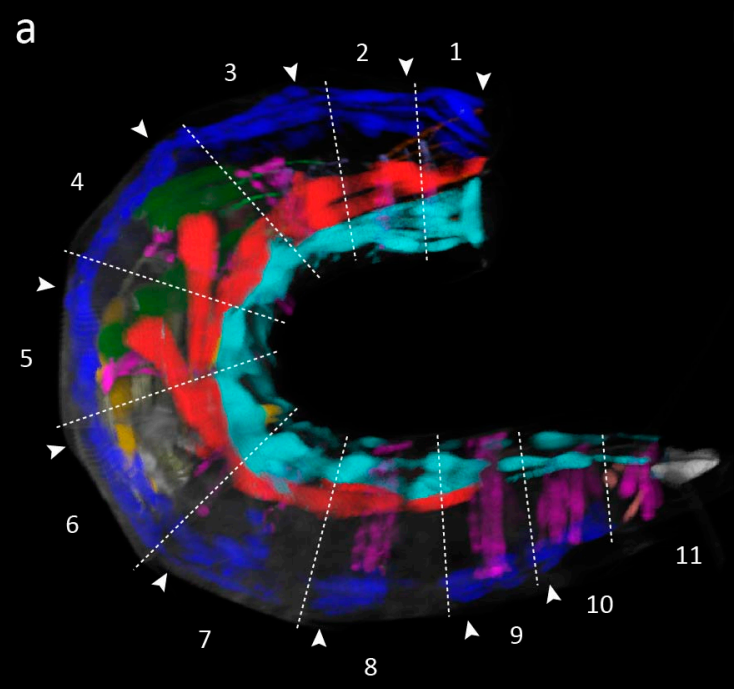

b

C
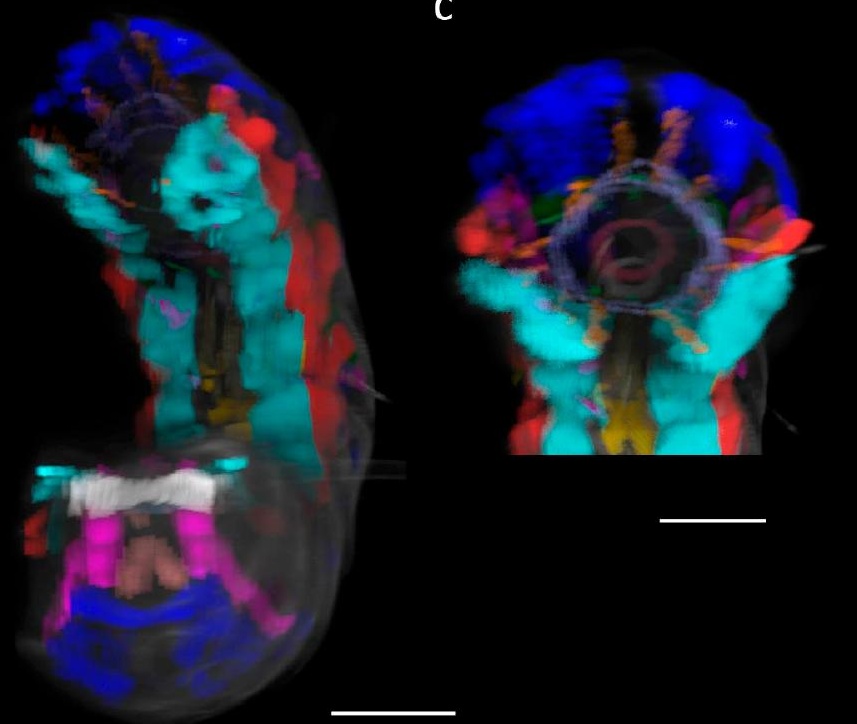

d

3

4

1

2

5

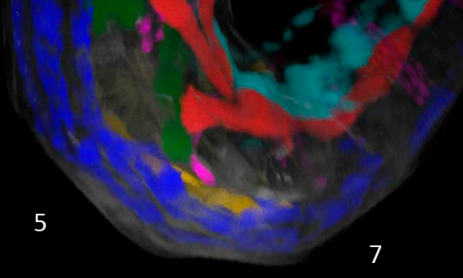

6 e

10

9

8

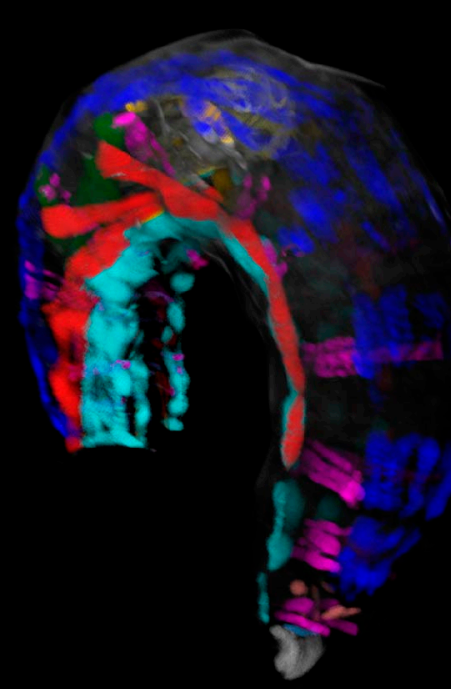

Introvert circular muscles

- Introvert short retractors

- Spinoscalid retractors

- Introvert long retractors

- Mouth cone retractors

- Pharyngeal bulb / Pharynx longitudinal muscles

Mouth cone circular muscles

- Lateral muscles

- Dorsoventral muscles

- Ventral longitudinal muscles

Dorsal longitudinal muscles

- Hindgut dilators

- Transverse muscles

- Longitudinal muscles segment 11 


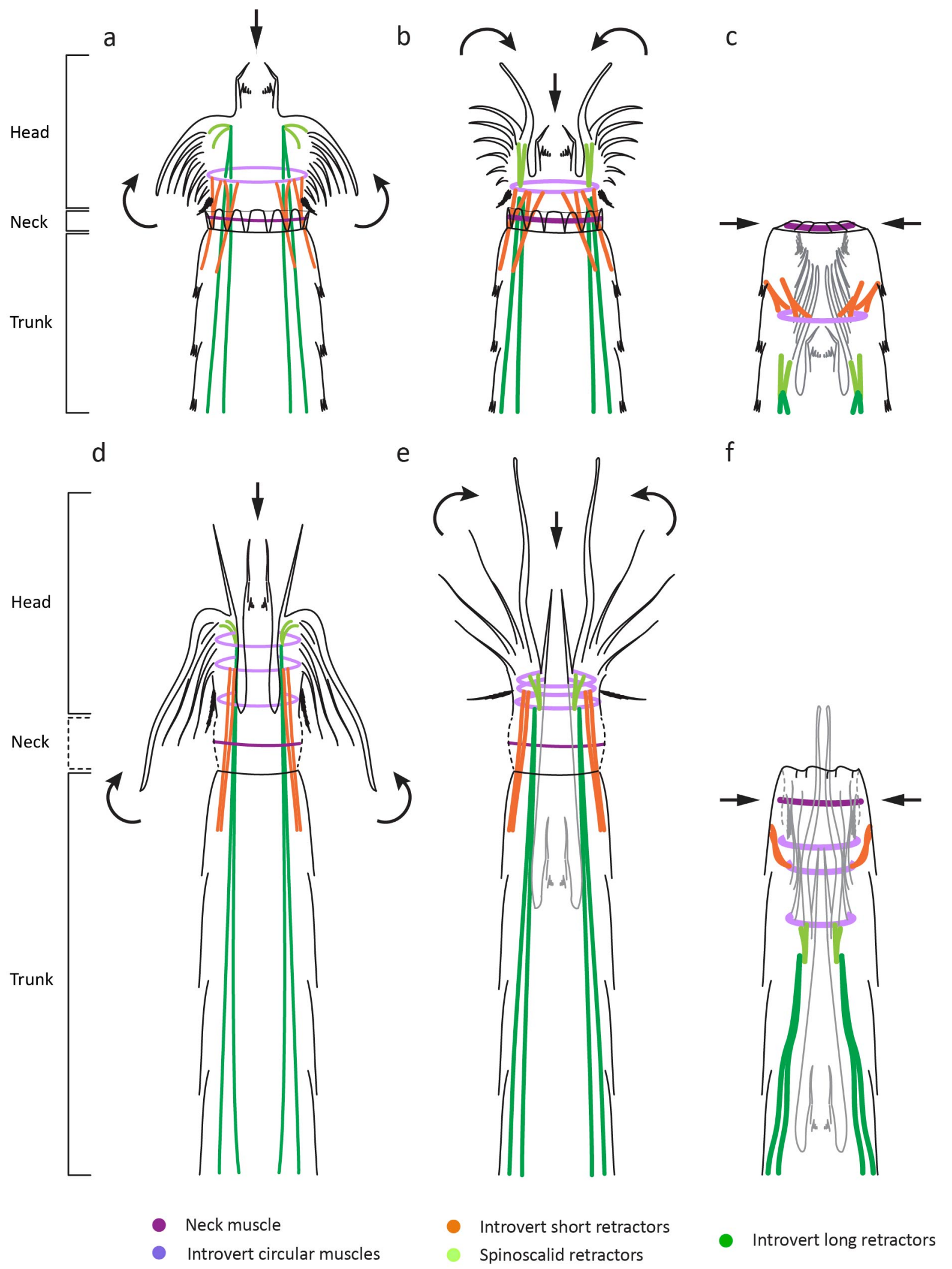

